\title{
Electromagnetic Mapping During Complex RF Ablations
}

\author{
Shimon Rosenheck, Jeffrey Banker, Alexey Weiss and Zehava Sharon \\ Hadassah Hebrew University Medical Center, Jerusalem, \\ Israel
}

\section{Introduction}

Electromagnetic mapping has made possible the routine approach to complex arrhythmia mapping. Originally, it was developed to facilitate accessory pathway location, but it only complicated solitary pathway ablation. Especially, with the introduction of atrial fibrillation ablation, the electromagnetic mapping has become an irreplaceable component of this procedure. Latter, this 3-dimentional mapping method facilitated ventricular foci ablation in patients with ventricular tachycardia. During the last decade, the application of this mapping method is continuously extended and applied to a large number of complex arrhythmia cases. The electromagnetic mapping is based on minimal magnetic field generation around the tip of the catheter and several antennas, located in a special hardware, called location pad, detect this field. In the near future the location pad will be replaced by an intracardiac detection system. As multiple antennas record the signal, the location pad precisely localizes the catheter tip. By apposition of a location on the endocardial surface and the catheter tip, a virtual map of the cardiac chamber is obtained. Multiple points are represented in space and finally, a continuous wall is completed. Moreover, the catheter records the electrical activity in its vicinity, and the electrical flow can be superimposed on the location in the space. A color-coding localizes the starting point of the arrhythmia and the current flow from it.

As of today, an advanced generation is used and data from other imaging systems are merged with the electromagnetic picture. First, magnetic resonance data was merged with the electroanatomic mapping, but today cardiac computed tomography and echo picture might also be merged. Using these merged pictures the anatomical presentation more accurately represents the anatomical structure.

\section{A brief history of catheter ablation}

The first type of energy used for catheter ablation to cure cardiac arrhythmias was the direct current (DC) shock delivered through the catheter tip in apposition to the desired site of ablation. By ablating the AV junction in supraventricular tachycardia, a reasonable rate control was achieved (Scheinman MM et al, 1982). The ablation of well-defined positioned accessory pathways could also be achieved by DC ablation (Morady F \& Scheinman MM, 1984). The DC shock can be adjusted by delivering different amplitude of shocks, but as soon as it was delivered there was no more way to titrate or cancel it. To achieve a titratable energy, a different source is needed and the radiofrequency energy has fulfilled this 
condition. At the end of 1980's the radiofrequency energy has been introduced into the clinical electrophysiology. With the advent of specific pathways ablation, the clinical electrophysiology has become a continuously extending brunch of the cardiology. The radiofrequency energy in opposite to the direct current shock, can be titrated, limited, suddenly discontinued and reapplied. For this reason, the RF energy is easily applied in clinical practice. The first accessory pathways ablations and AV Nodal pathways ablations were performed during the late 1980's and published for the first time in 1991 (Jackman WM et al, 1991: Calkins $\mathrm{H}$ et al, 1991). Since than, a vast amount of literature was published on this subject and almost all type of arrhythmia has become feasible for ablation. In Table $2.1 \mathrm{a}$ list of ablatable arrhythmic substrates is presented.

\begin{tabular}{|l|c|l|}
\hline \multicolumn{1}{|c|}{ Arrhythmia Type } & Fist performed & \multicolumn{1}{c|}{ Publication } \\
\hline WPW & 1989 & Jackman WM et al 1991; Clakins H at al, 1991 \\
\hline ANRT & 1989 & Lee MA at al, 1991 \\
\hline A Flutter & 1992 & Feld GK et al, 1992; Cosio FG et al, 1993 \\
\hline A Tachycardia & 1992 & Kall JG\& Wilber DJ, 1992; Walsh EP et al, 1992 \\
\hline VT idiopathic & $1991-1992$ & Kuck KH et al, 1991; Klein LS et al, 1992 \\
\hline VT in Heart Disease & 1992 & Morady F et al, 1993 \\
\hline A Fibrillation & 1996 & Haissaguerre M et al, 1998 \\
\hline VF idiopathic & 2001 & $\begin{array}{l}\text { Takatsuki S et al, 2001, Haissaguerre M et al, } \\
2002\end{array}$ \\
\hline
\end{tabular}

Abbreviations: WPW-Wolf Parkinson White Syndrome; AVNRT- AV Nodal Reentrant Tachycardia; A Flutter-Atrial Flutter; A Tachycardia-Atrial Tachycardia; VT-Ventricular Tachycardia; A FibrillationAtrial fibrillation; VF- Ventricular Fibrillation

Table 2.1. The table summarizes the types of arrhythmia treated with catheter ablation.

In accessory pathway ablation, the presumed location is meticulously mapped with a special developed steerable tip catheter. The pathways are located on the mitral or tricuspid rings, or in the septum separating the left and right heart. When the recoding from this site is satisfactory, RF energy is delivered for certain duration. If the accessory pathway conducts electricity in both directions, or at least, in the antegrade direction (from the atrium to the ventricle), the resting ECG shows a typical preexcitation pattern. Short PR interval and a widening of the QRS characterize this preexcitation. A typical delta wave is preceding the QRS and its direction depends on the location of the pathway. Wolf, Parkinson and White described this type of ECG in 1930 and if it is associated with palpitation is called WolffParkinson-White syndrome (Wolff L et al, 1930). During the RF energy delivery the preexcitation disappears and the ECG becomes normal. After the ablation, during temporary blockage of the AV node with intravenous adenosine injection, $\mathrm{AB}$ block is achieved, demonstrating the remaining conduction only through the AV junction.

However, in $50 \%$ of the patients the resting ECG is normal, but still the patient can develop supraventricular tachycardia. In this case, the accessory pathway conducts the electricity only in the retrograde direction (from the ventricle to the atrium) and is called concealed Wolff-Parkinson-White syndrome. The mapping is completed either during tachycardia or ventricular pacing. RF energy application eliminates the retrograde conduction without affecting the resting ECG.

Patients with dual AV Nodal conduction may develop supraventricular tachycardia based on reentry circuit in the AV Node. One of the pathways has slow conduction of the electricity and 
the other has fast conduction. If the refractoriness of these pathways and the conduction times are appropriate, the electric impulse may be conducted in a circuit constituted by this two pathways and the clinical expression will be supraventricular tachycardia with short VA time. A premature beat during unidirectional block in one of the pathways initiates the tachycardia. Different duration of refractoriness of these pathways creates the unidirectional block. Blocking one of these pathways will prevent induction of the tachycardia. RF ablation is based on the same principle: selective elimination of the conduction on one of these pathways. In the late 1980's the fast pathway was ablated (Lee MA et al, 1991). These fast pathways are located in the anterior site of the AV node very near to the proximal His Bundle. Although the success rate was very high, special attention was needed to avoid complete AV Block. After a year, the slow pathway ablation was described (Jackman WM et al, 1992). The slow pathway is located in the posterior AV nodal area, relatively far from the His Bundle. The ablation of these slow pathways is safer and today is routinely performed in most of the electrophysiology laboratories. After the ablation, the AV refractoriness prolongs and the AH interval (atrial-His conduction time) remains short immediately before the blocking.

The third classical ablation is that of typical atrial flutter (Feld GK et al, 1992, Cosio FG et al, 1993). In typical atrial flutter, a single electrical wavefront circulates in the perimeter of the right atrium. The area between the lower pole of the tricuspid valve and the inferior vena cava is called isthmus. A multipolar catheter on the lateral wall of the right atrium demonstrates the counter-clockwise or clockwise rotation during the flutter. Complete blocking of the isthmus, terminates the flutter. After the successful ablation, pacing at the coronary sinus osteum demonstrates the block, by conduction to the lateral wall only from above the tricuspid annulus.

In atrial tachycardia, idiopathic or peri-scar, and idiopathic ventricular tachycardia from right outflow tract or the basal left ventricle (fascicular), the atrial or the ventricular foci are ablated. The first three ablations, the accessory pathway (WPW) ablation, the selective or non selective AV Nodal pathways ablation and typical atrial flutter ablation are the classical ablations, which rarely if at all need other mapping methods, like the three-dimensional mapping methods. The atrial and ventricular tachycardia foci ablation is feasible in the majority of cases with "simple" electrophysiology mapping, like early activity, bracketing, entrainment, pace mapping, multi-pole catheter mapping, etc. However, occasionally, this mapping is not sufficient and three-dimensional mapping is needed (Marchlinski FE et al, 1998; Leonelli FM et al, 2001; Peichl P et al, 2003; Dong J et al, 2005). As we can notice, in the classical ablations, both the diagnostic test and the ablation procedure are focused on electrophysiology parameters. In atrial and ventricular tachycardia, although there are well defined electrophysiology maneuvers as previously mentioned, the more exact location of the focus and the demonstration of the ablation results demands the advanced electroanatomic mapping.

\section{The development of the electroanatomic mapping and the electroanatomic mapping guided ablation}

In the early 1990's, Ben Haim and his colleagues developed a new method of threedimensional mapping of a tubular or spherical organ. First it was presented in the NASPE meeting in 1996 (Smeets J et al, 1996; Ben-Haim SA et al, 1996a; Hayam G et al, 1996; Gepstein L et al, 1996), than published as a new method evaluated in animal model and human subjects (Ben-Haim SA et al, 1996b; Gepstein L et al, 1997, Shpun S et al, 1997; Gepstein L et al, 1998). In this method, the locator pads, located beneath the operating table, generate a week magnetic field. The magnetic field strength is between $5 \times 10^{-6}$ and $5 \times 10^{-5}$ tesla. A miniature sensor embedded in the body of the distal catheter collects these magnetic 
fields. As the fields vectors have different directions, computer integration of the data resolves the location and orientation of the sensor in space. During the same time, the distal electrodes, located on the catheter tip, record the electrical activity behind it. By collecting multiple points, the heart chamber anatomy and the local electrical impulse in amplitude and timing are superimposed. With higher number of points added, higher precision is achieved. The resolution of the sensor location in space is $<1 \mathrm{~mm}$. Finally, the electrical field propagation is presented on the virtual reconstruction of the heart chamber anatomy. If the amplitude is expressed, scar anatomy is obtained based on very low electrical activity on the scar. Moreover, a transitional region with increasing amplitude will interpose between the scar and normal tissue. In this type of mapping, invagination of conducting tissue in the scar, gaps and marginal zones may present the substrate of arrhythmias. Early in the development of the electroanatomic mapping, the scar mapping contributed to the understanding of the arrhythmia substrate and made possible non-specific scar ablation (Stevenson WG et al, 1998a; Stevenson WG et al, 1998b; Marchlinski FE et al, 2000; Sra J et al, 2001). However, the main development of the electroanatomic mapping happened with the use in atrial fibrillation ablation. After discovery of the triggers in the pulmonary veins, focal ablation was suggested, but the application of this ablation is limited and associated with an increased incidence of complication (Haissaguerre $M$ et al, 1998). The use of electroanatomic guided ablation offered ablation lines in the antrum of the veins and in this way the ablation is far from the vein itself and also significant debalking is added (Pappone $\mathrm{C}$ et al, 1999; Pappone $\mathrm{C}$ et al, 2000; Oral $\mathrm{H}$ et al, 2003). The ablation was extended to persistent atrial fibrillation and even to long-standing persistent cases (Nademanee K et al, 2004; Oral $\mathrm{H}$ et al, 2006; Takahashi $\mathrm{Y}$ et al, 2007). This addition contributed to development of this mapping. Additional mapping methods were developed and promoted in parallel with the original electromagnetic mapping, the CARTO mapping. Finally, the list of ablatable substrates has continuously increased and today includes beside atrial fibrillation and ventricular tachycardia in patients with or without structural heart disease, also atrial tachycardia, recurrent and refractory atrial flutter, idiopathic ventricular fibrillation (Knecht $S$ et $\mathrm{al}, 2009$ ) and more recently, the substrate of Brugada syndrome (Nademanee K et al, 2011). The following sections will describe in details the use of the mapping in each of these indications.

\section{Right atrial tachycardia}

The mechanism of right atrial tachycardia may be an autonomic focus or reentry around a physical obstacle, most commonly an iatrogenic scar or a post-infectious scar.

\subsection{Right atrial tachycardia-reentrant type}

For mapping the scar, bipolar voltage mapping is needed. Figure 4.1 shows two views obtained during atrial tachycardia ablation in a 32 year old man, who had a remote atrial septal closure surgery. During the surgery the lateral wall in the right atrium was opened and the septal defect was closed. On a recent echo, no interatrial shunt could be seen demonstrating lack of atrial septal defect and late success of the surgery. However the patient developed incessant and persistent atrial tachycardia. During the electrophysiology study, the right atrium was mapped using bipolar voltage mapping. This technique allows determination of the scar, as on the scar the electrical activity is practically non-existent. We defined everything bellow $0.04 \mathrm{~V}$ as scar and assigned with red color. The normal tissue is defined everything above $0.47 \mathrm{~V}$ and assigned with purple. The tissue in between them is the transition zone. As evident from the picture, the two red areas were connected with a continuous ablation line obtained with a point-by-point ablation. 

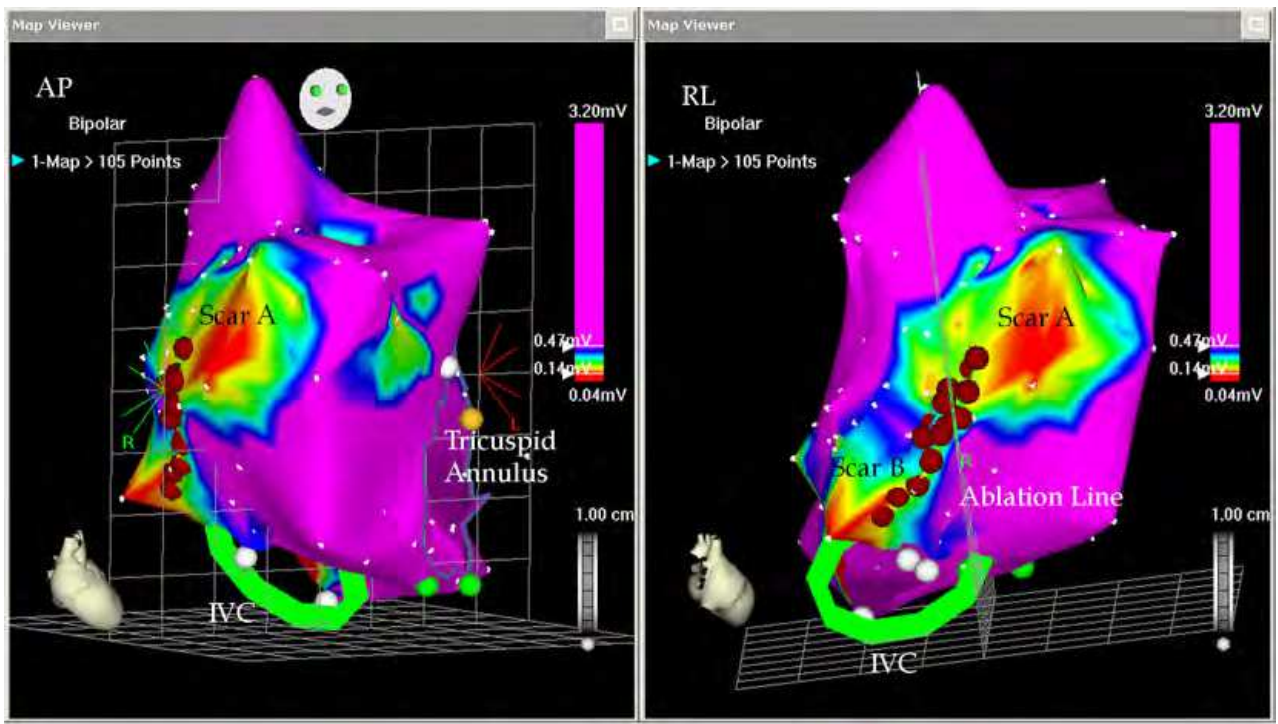

Fig. 4.1. The picture shows the voltage mapping of the right atrium with two scars on the lateral wall, a large (Scar A) and a small one (Scar B). The small one (Scar B) is connected to the Inferior Vena Cava. A small strip on normal myocardium separates the scars and this strip was transected with the ablation line. Annotations: AP- antero-posterior (the left picture); RL- Right lateral (the right picture). For further explanation see the text.

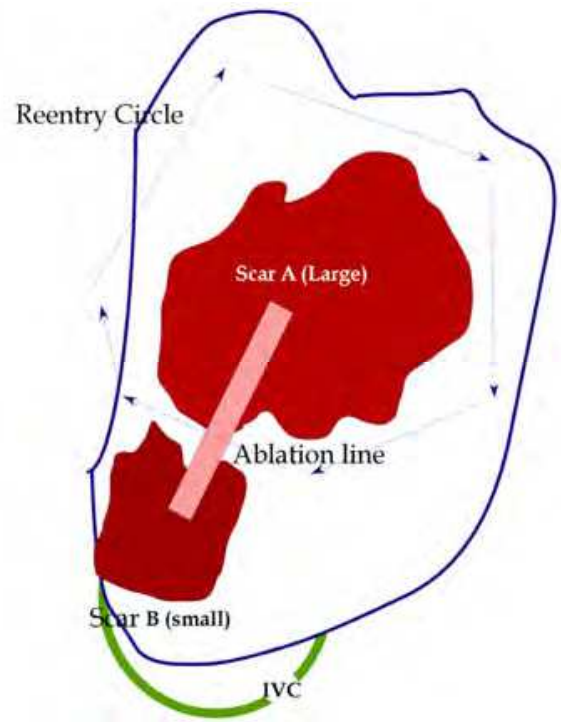

Fig. 4.2. Schematic presentation of picture 4.1; the picture shows the two scars, a large and a small one. The IVC ring limits the small one. To interrupt to reentry circle the ablation line connects the two scars. 
During two-year follow-up the patients is free of any arrhythmia. This case demonstrates the of electro-anatomic mapping used for scar dependent atrial tachycardia ablation.

\subsection{Right atrial tachycardia-automatic focus type}

The next case will exemplify the ablation of automatic paroxysmal atrial tachycardia. The patient is a 17-year-old male patient with a history of palpitation and documented supraventricular tachycardia. Electrophysiology study demonstrated supraventricular tachycardia with long VA time and the ventricular rate was dictated by the atrial rate. Occasionally 2:1 AV conduction and even Wenkebach conduction was documented. The final diagnosis was right atrial tachycardia originating in the inferior third of the crista terminalis. Ablation was focused on the earliest atrial activity using a duodecapolar catheter. The tachycardia terminated during the RF application and has become noninducible. However, after 2 weeks the patient again experienced palpitation and again a similar arrhythmia was documented. The patient was referred for a second ablation this time CARTO guided. The tachycardia was again easily induced with atrial overdrive pacing, but not with atrial premature beats. Figure 4.3 shows the CARTO mapping.

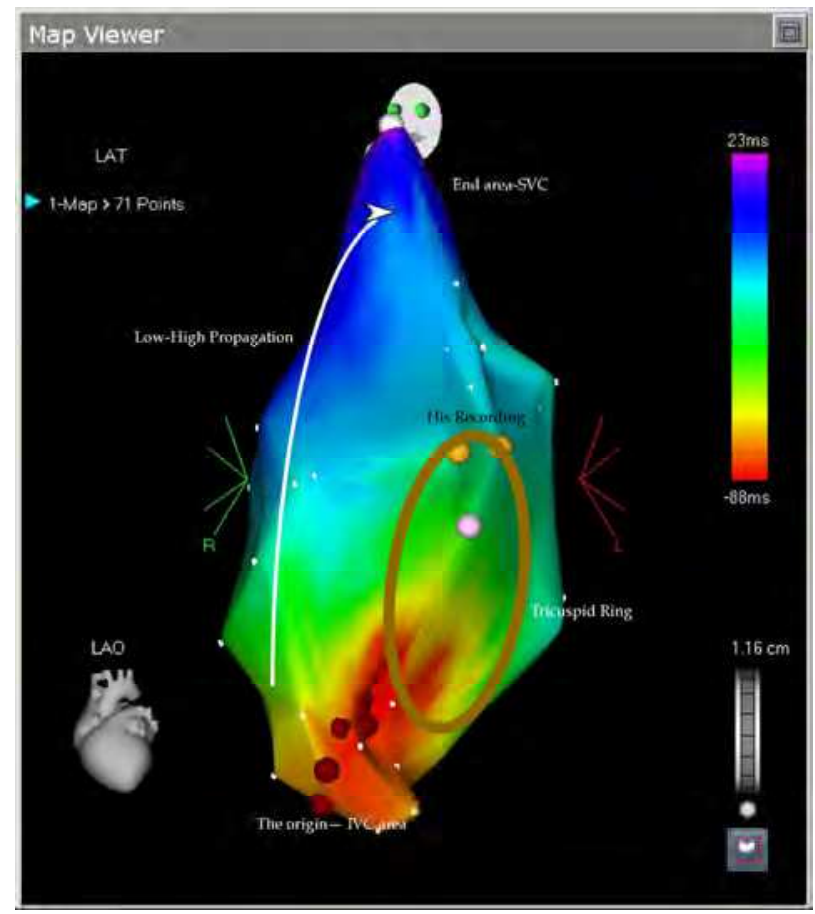

Fig. 4.3. Right Atria Tachycardia with the origin at the Inferior Vena Cava (IVC) area and the activation terminating at the Superior Vena Cava (SVC) area. This is a propagation map and the colors define the timing at each area. The red is the earliest time $(-88 \mathrm{msec})$ and the purple the latest time $(+23 \mathrm{msec})$ compared to the reference catheter. The white line with the arrow shows the activation direction. The red points in the origin area show the Radiofrequency application sites, which terminated the tachycardia rendering it non-inducible. 
In this case, voltage mapping cannot be used as no scar could be mapped and the patient had no any previous cardiac procedure except the ablation procedure. For this reason, a propagation mapping was used. During this mapping the virtual reconstruction of the right atrium is completed parallel with accurate timing detection by comparing the activation time with the timing on a reference catheter, in this case in the coronary sinus osteum. The timing of the points located with the mapping catheter is compared with the reference catheter and is assigned with red color if it is early and purple if it is late. In between are the other colors like yellow, green and blue. Finally, a cine presentation shows the flow of the electrical activity, starting at the red point and terminating at the blue points. The red points are the area focused for ablation. As evident in Figure 4.3, the origin is well determined and ablation at this point again terminated the tachycardia leaving it noninducible. During the follow-up the patient is asymptomatic, practicing nonprofessional sportive activity.

These two cases exemplify not only two types of right atrial tachycardia, but also two methods of mapping. If a scar is to be mapped, the amplitude of the electrical activity will discriminate it from the normal tissue with clear demarcation. The reentry can be completed around a scar and by connecting the scar to a non-conducting tissue will prevent the reentry. This map is called, voltage-map, or scar mapping. In contrary, if the tachycardia is generated by an automatic focus, the earliest activation will reveal the origin of the tachycardia and the ablation may be focused to it. This is achieved by determining the timing at each point and the map is called, flow-map.

These two cases are presenting the classical types of atrial tachycardias. However, occasionally the diagnosis is not so simple and the first impression may be misleading. The electro anatomic mapping may elucidate the diagnosis and make possible the correct ablation. In the next subsection such a complex case is presented.

\subsection{Atrial flutter or not flutter that is the question}

A 28-year-old man presented with an ECG showing typical atrial flutter and was referred to radiofrequency ablation. He was in sinus rhythm when admitted for the ablation and the inferior isthmus (between the tricuspid ring and the inferior vena cava) was ablated using a $10 \mathrm{~mm}$ tip ablation catheter, a duodeca mapping catheter on the lateral wall and a quadripolar pacing-mapping catheter in the proximal coronary sinus. The ablation was performed during coronary sinus pacing and the original collision on the lateral wall was abolished demonstrating the block bellow the valve. Pacing from the coronary sinus and from above the inferior vena cava approved the block in the isthmus. Although the bidirectional block was persistent the patient had additional episode of "typical atrial flutter". In a second electrophysiology study the block in the isthmus was persistent and the patient had still inducible arrhythmia (Figures 4.4 and 4.5). Although the diagnosis of atrial flutter was attempting the duodeca catheter recording showed a big delay in the isthmus area during the tachycardia. This is not acceptable in typical atrial flutter or at least during an isthmus dependent flutter. Figure 4.5 shows details of the duodeca catheter recording during the atrial tachycardia-the last 10 tracings on Figure 4.4. The earliest point on the lateral wall is on pole D5-6. Pole D1-2 records from the median site of the isthmus block and pole D3-4 from the lateral site. The double arrow shows the big delay demonstrating the isthmus block during the tachycardia and non-isthmus dependent tachycardia. For this reason, CARTO mapping was initiated. 


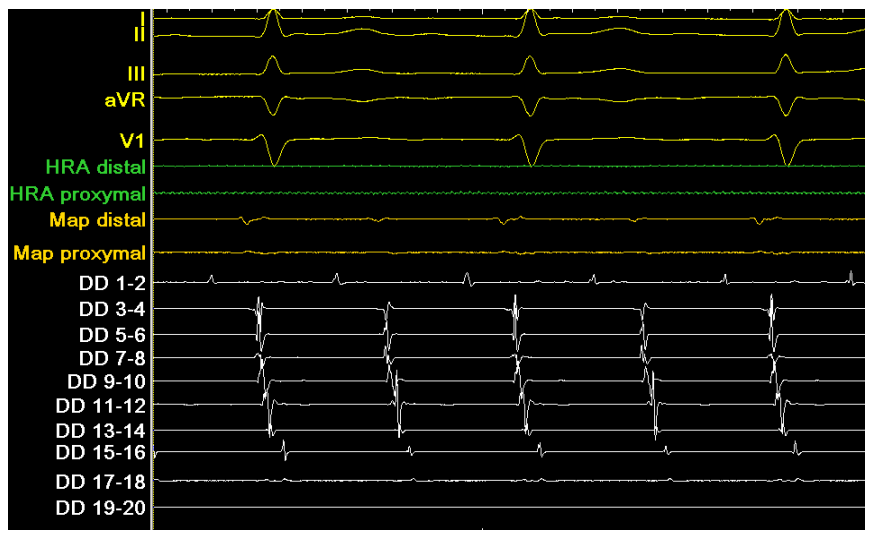

Fig. 4.4. The tracing shows a regular tachycardia, recorded at $100 \mathrm{~mm} / \mathrm{sec}$. The first 5 tracing are surface electrograms $L_{1}, L_{2}, L_{3}, A V R$ and $V_{1}$. The next two belong to the right atrial tracing as reference for the CARTO mapping (not recording temporarily), than the mapping catheter and finally 10 tracings from the duodeca catheter deployed on the right lateral wall of the right atrium. The tracing on the duodeca catheter reveals unidirectional conduction suggesting atrial flutter. However, the tracing at DD1-2 is extremely delayed. As DD1-2 is medial to the isthmus block line and DD3-4 lateral, this delay demonstrates isthmus block during the tachycardia (See also Fig 4.5)

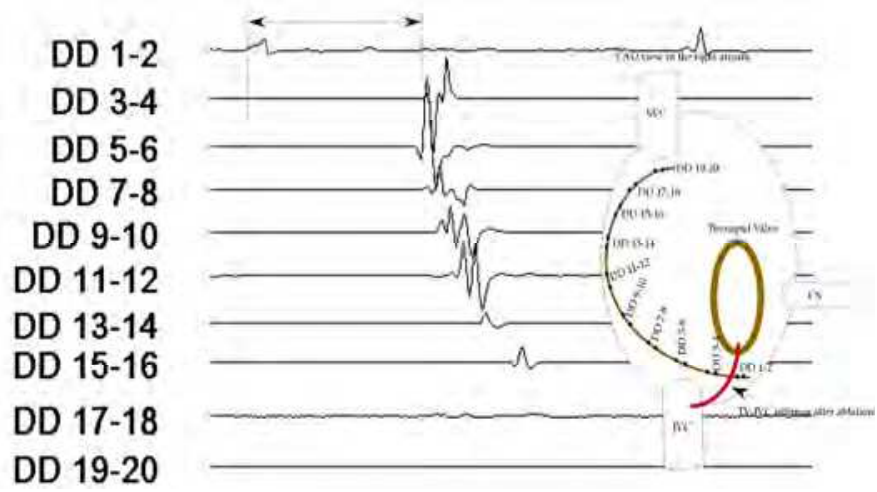

Fig. 4.5. The figure shows the tracing on the duodeca catheter at $200 \mathrm{~ms} / \mathrm{min}$ recording speed. The cartoon inserted on the tracing shows the right atrium, IVC, SVC and CS. The isthmus block line is also depicted. The position of 10 bipolar poles is also shown. DD 1-2 is medial to the block line and all the other 9 poles are lateral to the line. On the tracing, a long delay is between DD 1-2 and 3-4 demonstrating the persistence of the block during the tachycardia, which is not compatible with typical atrial flutter.

A CARTO mapping demonstrated tachycardia originating from the lateral border of the block line in the isthmus (Figure 4.6) and was abolished by focal ablation using the area determined by the flow-map (Figure 4.7 and 4.8). The surface ECG was misleading and the real arrhythmia was atrial tachycardia and not atrial flutter! The electro-anatomic mapping made possible the correct diagnosis and finally the appropriate treatment. 


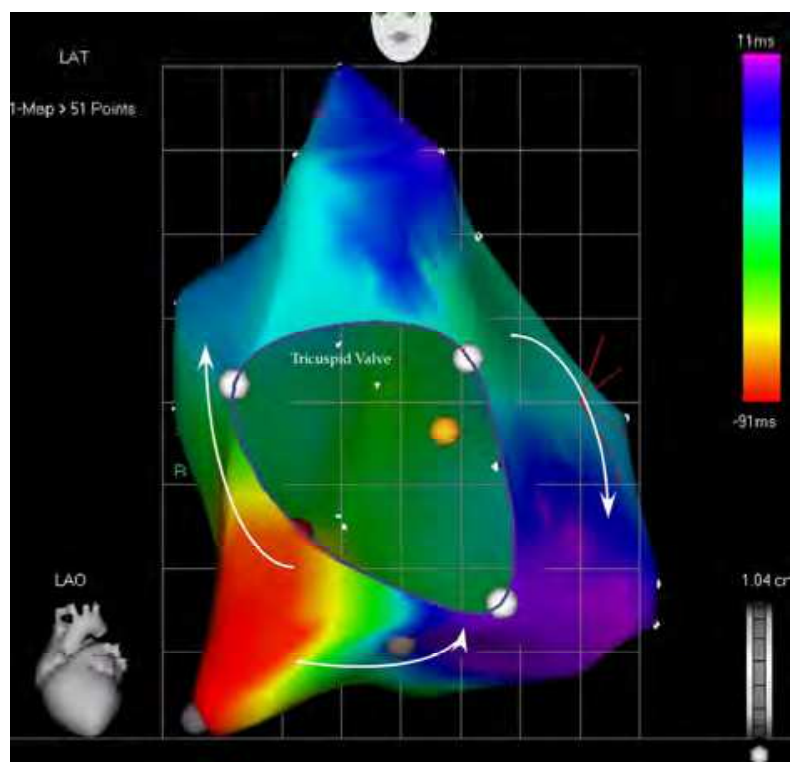

Fig. 4.6. Flow map during the tachycardia showing the early activation lateral to the isthmus line (purple color). The white arrows depict the current flow, simulating the flutter activation pattern except in the area between the origin (red color) and isthmus line (purple color) where a slow conduction in the opposite direction is clearly revealed. The isthmus is invaded from both sites.

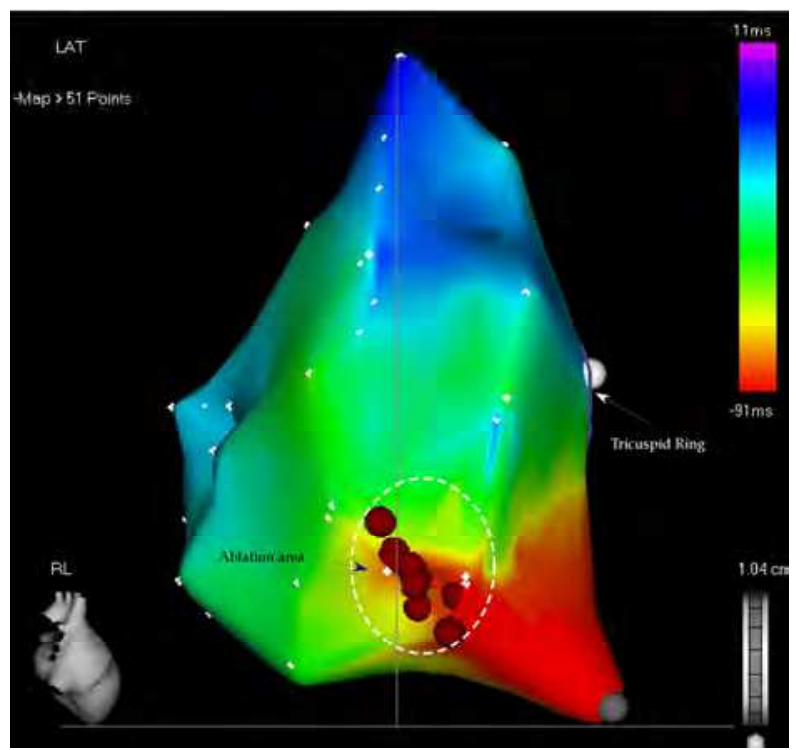

Fig. 4.7. The flow map from right lateral view is superimposed with the ablation mark signs. During the applications in this area the tachycardia terminated as shown in Figure 4.8. 
This is an illustration of the importance of electro-anatomic mapping in this case as the surface ECG suggested typical atrial flutter and apparent recurrence after successful ablation of the cavo-tricuspid isthmus. At the first glance, the recording suggests atrial flutter, but there is a sudden delay between DD 3-4 and DD 1-2. This is possible only if the isthmus block is persistent and the catheter is laid over the block line with the tip over the line and the rest of poles before the block line. If the tachycardia can continue despite the block in the isthmus, it cannot be isthmus-dependent flutter. The electro-anatomic mapping revealed the correct diagnosis and made possible the appropriate ablation.

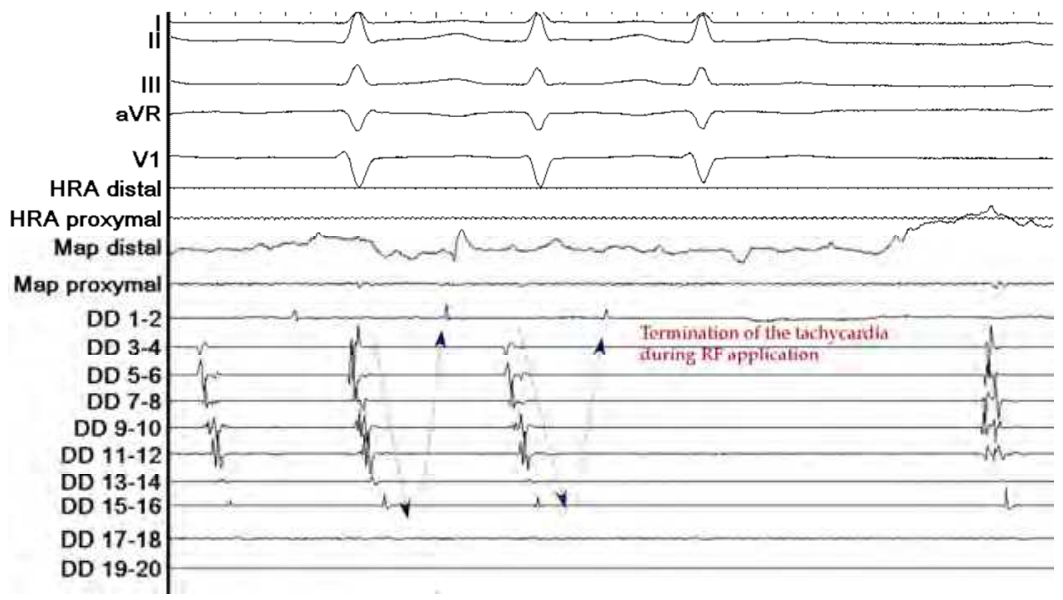

Fig. 4.8. In this tracing during the radiofrequency energy application, the tachycardia terminates and at the right side of the tracing the first sinus beat is seen. Of note, the tachycardia termination is sudden and not caused by ectopic activity, but only by the ablation. During the termination the last recording is from DD 1-2, demonstrating that the origin was between DD 3-4 and 5-6 and the last activation is on DD 1-2 (See Figure 4.6).

\section{Left atrial tachycardia}

Left atrial tachycardia may be of the same origin like the right atrial tachycardia. The automatic form mostly originates in the pulmonary veins, but the reentry forms originate in the atrial tissue like the reentry tachycardia in the right atrium. The most common form today is related to catheter ablation of atrial fibrillation, which will be discussed and presented within a next section on atrial fibrillation ablation. A rare form is the para-septal atrial tachycardia, which interestingly is associated with patent foramen ovale. For this reason, to map and ablate it, the septum is easily passed and the left atrium is easily mapped. The next presentation will exemplify it and will present the use of electro-anatomic mapping to determine the earliest activation point.

A 48 year old woman was referred because a persistent form of atrial tachycardia. First right atrium was mapped and the earliest activation was on the septal area. The activation time was at about zero time when compared to the reference catheter located in the coronary sinus osteum. By mapping the septum at the fosa ovalis, the catheter passed to the left atrium without need for standard septal puncture. The left atrium was mapped. A fast map 
was obtained, than the activation was superimposed on it. An early activation was mapped on the anterior wall, immediately above the mitral ring (Figure 5.1). At this point the ablation terminated the incessant atrial tachycardia.
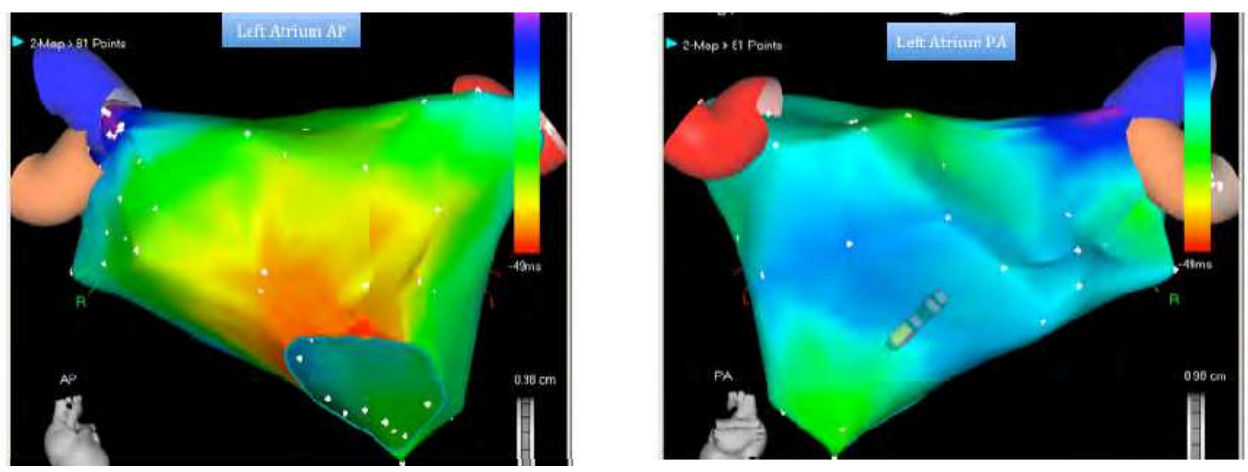

Fig. 5.1. The picture shows the left atrial flow map during incessant tachycardia. The activation time in the anterior wall and above the mitral ring was $-43 \mathrm{msec}$ (red color). On the posterior wall the activation times were all longer than $0 \mathrm{msec}$ (compared to the reference catheter at the coronary sinus osteum. The area above the right pulmonary vein is as late as $53 \mathrm{msec}$ after the activation on the reference catheter (purple color).

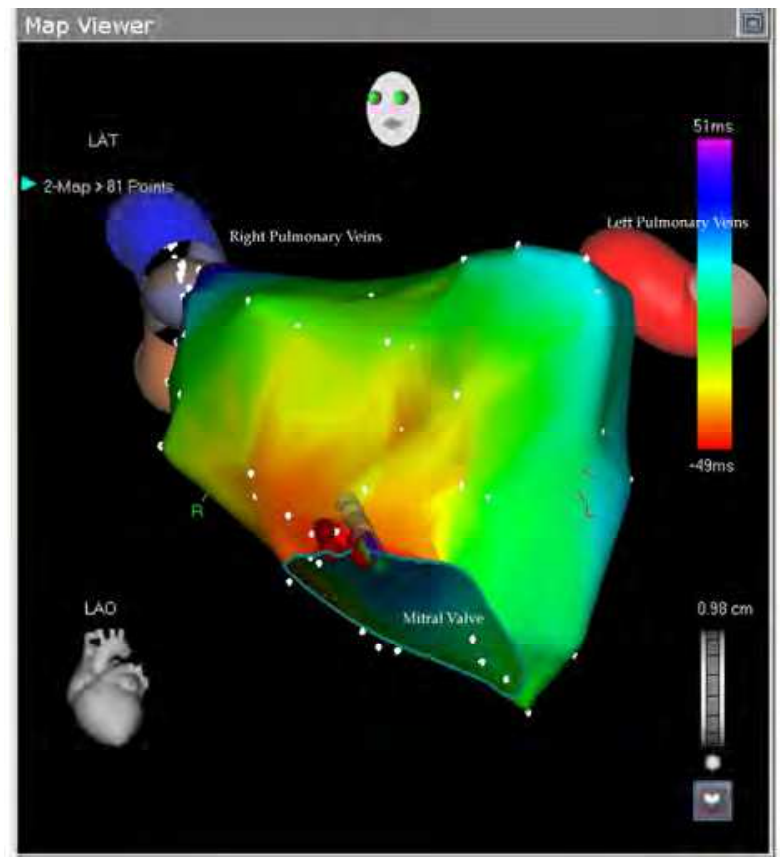

Fig. 5.2. The figure shows the virtual reconstruction of the left atrium during the tachycardia with the earliest point in red color. The catheter tip is pointing to that area. The ablation sites are shown. The tachycardia terminated with these ablation points. 
As of today, the published information on electro-anatomic mapping during atrial tachycardia ablation is scars and limited. However, the clinical application is well known and rich and the accumulated and published knowledge is worth to mention. Atrial tachycardia is encounter in both pediatric and adult patients. We have information on the use of electro-magnetic mapping in both groups. In right atrial tachycardia, the use of this mapping adds a significant degree of accuracy and, just like in our patient described in subsection 4.3, rarely the electro-magnetic mapping adds to the correct diagnosis. In patients with incessant focal tachycardia, the electrophysiological maneuvers may be enough but in patients with scar related tachycardia, this mapping has irreplaceable value. In incessant focal tachycardia, the earliest activation in the Crista Terminalis area or along the tricuspid ring will reveal the origin and radiofrequency energy application will terminate it and total cure is achieved. However, if the tachycardia persists or reoccurs, 3D mapping is justified (Subsection 4.2). As previously mentioned, the activation map helps to localize the origin of the tachycardia. In scar related reentrant tachycardia, the scar is delineated and a narrow isthmus in between them is ablated (Subsection 4.1). Voltage mapping delineates the scar, and amplitude lower than $0.14 \mathrm{mV}$ suggests scar.

The published studies involved a limited number of patients, 7 to 120 . Focal tachycardias in the right atrium are ablatable with success rate $>90 \%$ (Kottkamp $\mathrm{H}$ et al, 1997; Marchlinski F et al, 1998; Iwai $S$ et al, 2002). The same success rate may be achieved in macroreentrant atrial tachycardia related to post-surgical scar (Iwai S et al, 2002). In the left atrium, focal tachycardias were localized to mitral annulus, roof, posterior wall, appendage and septum (Dong J et al, 2005). Left septal atrial tachycardia is rare and the electroanatomic mapping facilitates its ablation (Marrouche NF et al, 2002). Atrial tachycardia originating in the mitral annulus is also rare and the electro-anatomic mapping also facilitates its ablation (Kistler PM et al, 2003). Our patient presented in section 5 had also tachycardia originating from the mitral annulus (Figures 5.1 and 5.2). In pediatric patients, the acute success is significantly higher with the electro-anatomic mapping compared to standard electrophysiological mapping and the recurrence rate was lower (Cummings RM, 2008).

In all these conditions, the electroanatomic mapping for ablation of all types of atrial tachycardia in the clinical practice is firmly established.

\section{Atrial fibrillation ablation}

Atrial fibrillation is the most common arrhythmia an presents a great challenge for any cardiologist and even more for the clinical electrophysiologist. This arrhythmia has a very erratic response to antiarrhythmic treatment and for this reasons a non-medical treatment is demanded. Device therapy did not prove to be an effective alternative to the mediocre medical treatment. For this reason, the ablative opinion is an attractive alternative.

Haissaguerre and his colleagues, by investigating the mode of initiation of paroxysmal atrial fibrillation, discovered that the trigger for this type of arrhythmia originates, in the majority of the cases, in the pulmonary veins (Haissaguerre $\mathrm{M}$ et al, 1998). Focal ablation of these foci, as a logical next step, turned to be complicated with damage to the vein, narrowing with significant and symptomatic increase in the pulmonary pressure. The electrical connection between the pulmonary vein and left atrium is through distinct pathways (Ehrlich JR et al, J Physiol 2003). Electrical disconnection of these veins avoided this damage and offered the same result. However, the recurrence and occasional pulmonary stenosis were still encountered. In 1999, Pappone and his colleagues suggested 
a different approach to disconnect electrically the pulmonary veins (Pappone $\mathrm{C}$ et al, 1999; Pappone C et al, 2000; Pappone et al, 2004). This method is based on electroanatomic mapping. The left atrium is approached by passing the inter atrial septum using the Brockenbrough method and the left atrial mapping is completed by virtual reconstruction of the atrial walls and tagging the veins and the mitral annulus. The ablation includes circles around the pulmonary veins and lines connecting the mitral annulus with the ablation line around the left lower pulmonary vein and lines connecting the left and right ablation rings around the veins. In patients with paroxysmal atrial fibrillation, this type of ablation was superior to the pulmonary vein disconnection, with higher success rate and lower recurrence rate after one year (Oral H et al, 2003). Moreover, in patients with persistent atrial fibrillation, circumferential pulmonary vein ablation was superior to amiodarone treatment in preventing recurrence of the fibrillation (Oral $\mathrm{H}$ et al, 2006; Pappone $C$ et al, 2006). Multiple escalated methods exemplify the problematicity of the ablation in patients with long persistent atrial fibrillation (Oral H et al, 2006; Takahashi Y et al, 2007; Satomi K et al, 2008). However, consensus was achieved on the necessity of catheter ablation of atrial fibrillation (Calkins $\mathrm{H}$ at al, 2007).

Following we will present several patients with atrial fibrillation and electro-anatomic guided ablation.
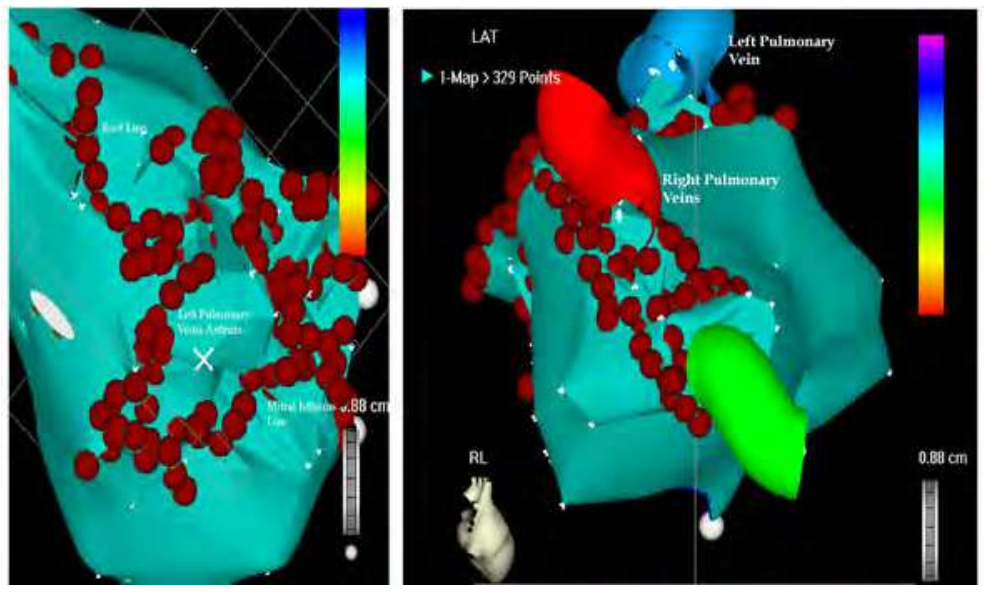

Fig. 6.1. The picture shows the ablation lines around the common left entrance and the two right veins. The lines are continuous.

SB 74 year old woman with a long history of paroxysmal atrial fibrillation on multiple antiarrhythmic medication including beat blockers, calcium channel blockers, Propafenon, Flecainide, Amiodarone all turned to be ineffective. The etiology of the atrial fibrillation was hypertension treated with multiple drugs. Finally she was referred to catheter ablation of atrial fibrillation. In the mean time the fibrillation converted to persistent. An ECHO showed normal systolic left ventricular function with decreased diastolic function, enlarged left ventricle with minimal mitral regurgitation. Patten Foramen Ovale with small left to right shunt was demonstrated. During the ablation, the septum was easily passed and the left atrium was reconstructed using anatomical map as she was in atrial fibrillation. The veins were tagged and the mitral annulus was reconstructed. The veins were circumvented with ablation points 
and the roofline and mitral isthmus lines were completed. When the radiofrequency was delivered in the junction between the roofline and right superior pulmonary vein the patient converted to sinus rhythm after 2 months of atrial fibrillation. Figure 6.1 shows the ring around the left veins and the right veins; Figure 6.2 shows the posterior view of the left atrium after the ablation. The mapping and ablation were done with CARTO EXP 7. She was in sinus rhythm 5 years after the ablation and during her last follow-up 3 years ago.

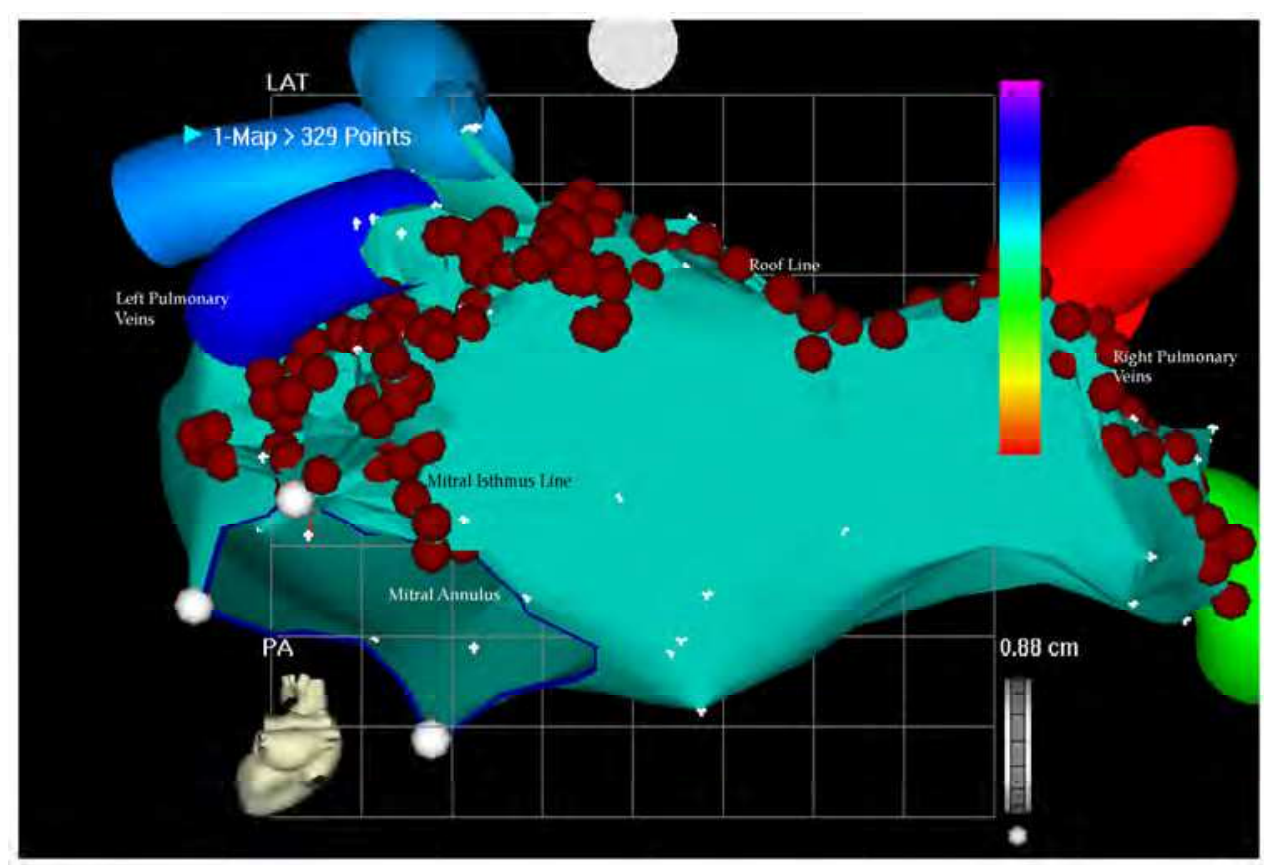

Fig. 6.2. The enlarged left atrium in a posterior view shows the rings around the pulmonary veins, the roofline and the mitral isthmus line. At least two lines connect the peri venous ring to the mitral annulus. There are 3 large left veins with a common entrance to the left atrium. The mapping is an anatomical map different from the mappings in atrial tachycardia ablation (Sections 4 and 5).

MD is 81-year-old man with persistent atrial fibrillation failing multiple medical treatments. He had long history of supraventricular tachycardia and had a successful slow pathway ablation 8 years ago. Two years ago presented with symptomatic atrial fibrillation. Medical treatment with beta-blockers, Propafenon, Flecainide were not effective and Amiodarone was discontinued because hyperthyroidism. As medical treatment had to discontinued because lack of efficacy or side effects he was referred to catheter ablation. At the admission he was in persistent atrial fibrillation for 3 months and without antiarrhythmic treatment. The transseptal catheterization was performed safely under intra cardiac echo guidance. After the ablation he converted to sinus bradycardia. Figure 6.3 shows the ablations lines in the left atrium and presents new modes of mapping (fast map).

SS is a 68-year-old man with long history of atrial flutter and fibrillation and hypertension. In 2002 he had a successful atrial flutter ablation. In 2004 he had catheter ablation of atrial 
fibrillation using the point-by-point method. Until recently he was in stable sinus rhythm when 3 months ago presented in the follow-up clinic with atrial fibrillation. Anticoagulation was started and referred for a second ablation. In the new mapping there was no electrical activity in the veins, on the posterior wall, but at several points around the veins was a low amplitude regular activity and all this places were ablated again. In the next figures the two mappings will be compared in the same patients emphasizing the advance in the mapping methods. The patient has common entrance of both left and right pulmonary veins. The intracardiac echo used during the second ablation in 2011 approved this anatomical variance.

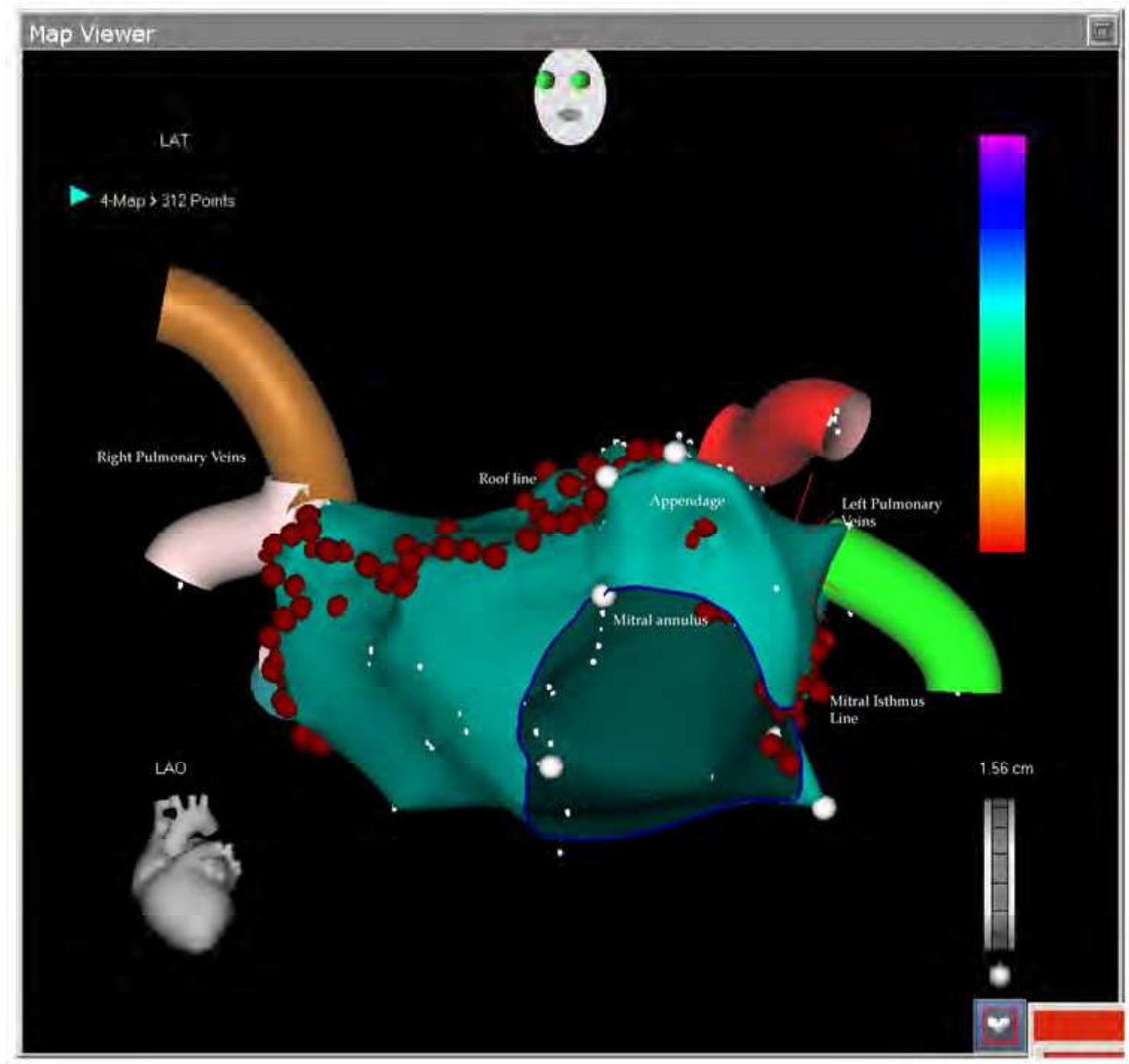

Fig. 6.3. The figure shows 20 degree left anterior view of the left atrium. The appendage covers the ablation ring around the left veins. The atrium is minimally enlarged. There is a common right entrance and two separate left veins. This map was performed using the fast map mode, a new future of the electro-anatomic mapping. The atrial anatomy much more resembles the other imaging models. The lines are continuous and the veins are completely isolated with no residual electrical activity in the veins or posterior wall. The mode is new and for this reason the follow up after the ablation is only 3 months, however the patient is in sinus rhythm. 


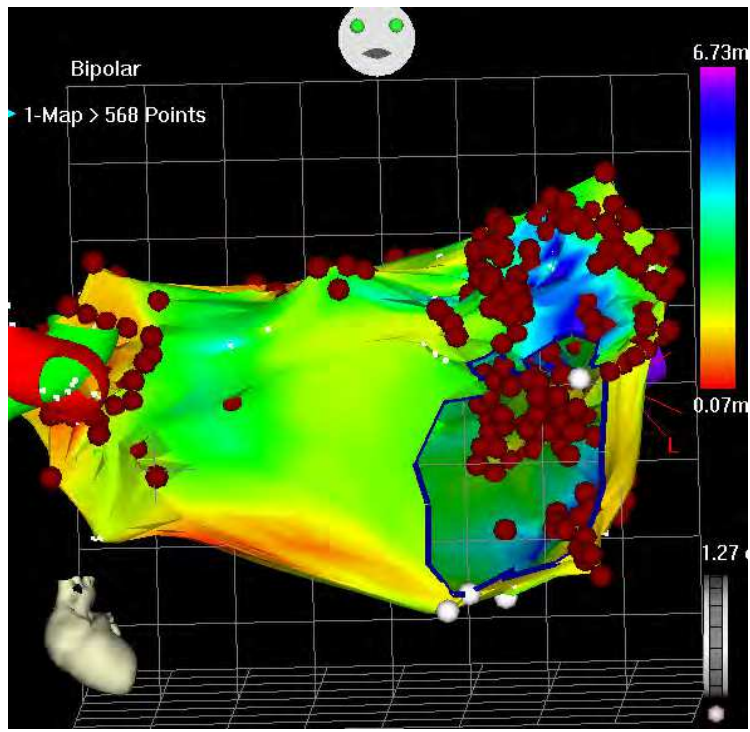

Fig. 6.4. The figure shows the anterior view of the left atrium recorded in 2004 using the point-by point method. The patient was in sinus rhythm during the procedure. A large number of ablation sites are seen through the mitral valve from inside the atrium. The left atrium is not enlarged. The left ablation lines are heavy and the right ablation lines are discrete. The roofline is slightly posterior an not present in this picture.

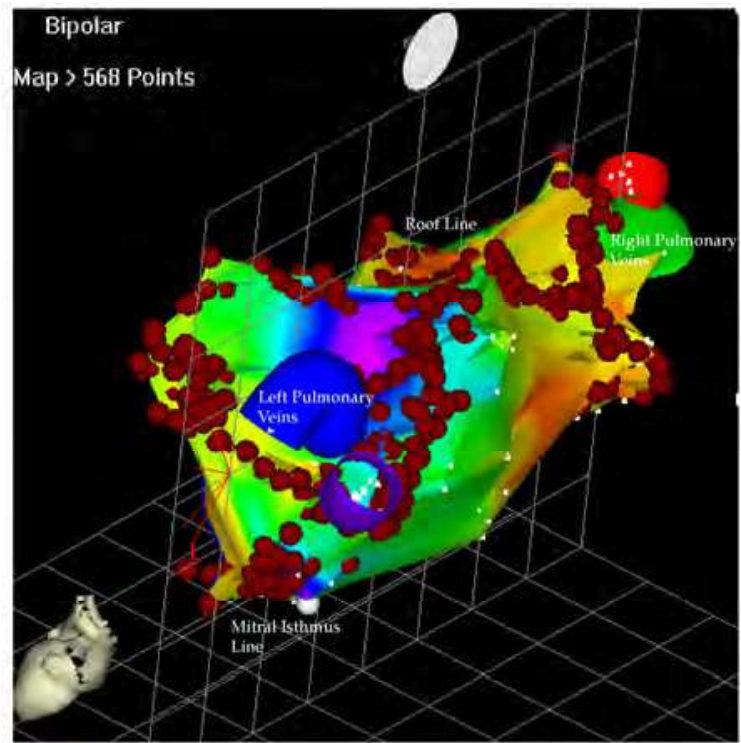

Fig. 6.5. This is a posterior view recorded during the first ablation procedure. The ablation lines are clearly seen and are heavy in the left side and discrete in the right side. The voltage amplitude in the posterior wall is low (red color). 
The next figure (6.5) shows the ablation lines in the posterior view and also the roofline not seen in Figure 6.4. Following the ablation the atrial fibrillation was not inducible. The areas around the veins were quiescent from any electrical activity. As the patient had a previous cavo-tricuspid isthmus line ablation, atrial flutter could also not be induced. As mentioned above, after 7 years the patient developed again atrial fibrillation, this time persistent and not paroxysmal. The following pictures will exemplify the second ablation procedure, with a more advanced electro-anatomic mapping system (Figures 6.6 and 6.7).

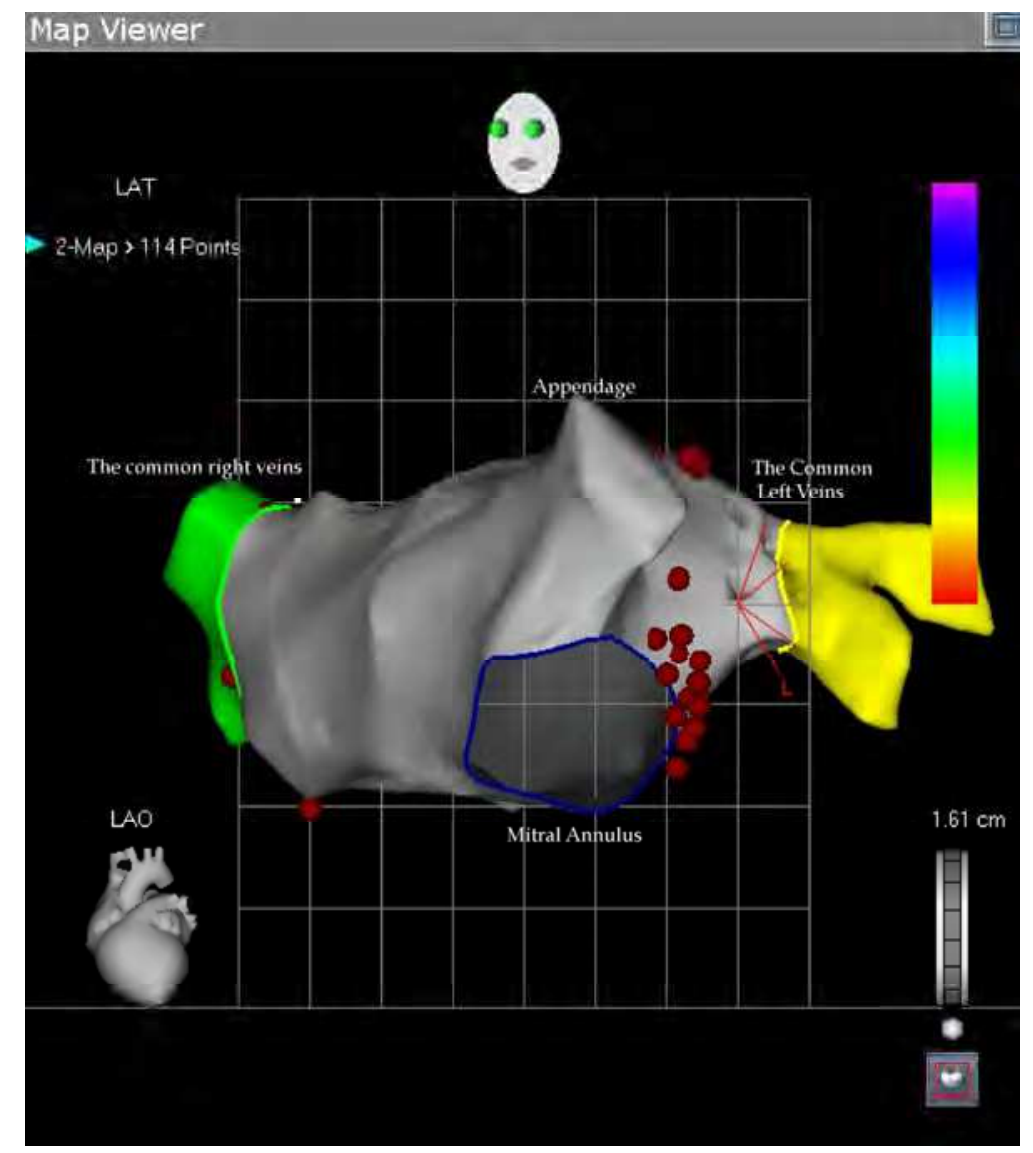

Fig. 6.6. The picture shows the left atrium using the fast map technique. This is the same left atrium like in Figures 6.4 and 6.5, just obtained 7 years latter and using more advanced method of mapping. The veins with common entrance are in colors, left with yellow and right with green. The mitral isthmus was reinforced with several ablation points and the left upper vein is also reinforced at the junction with the roofline were low amplitude relatively slow and regular activity was recorded. The ablation canceled this activity and the entire vein was free of any electrical activity. The next figure will show the areas with residual activity on the right side. 


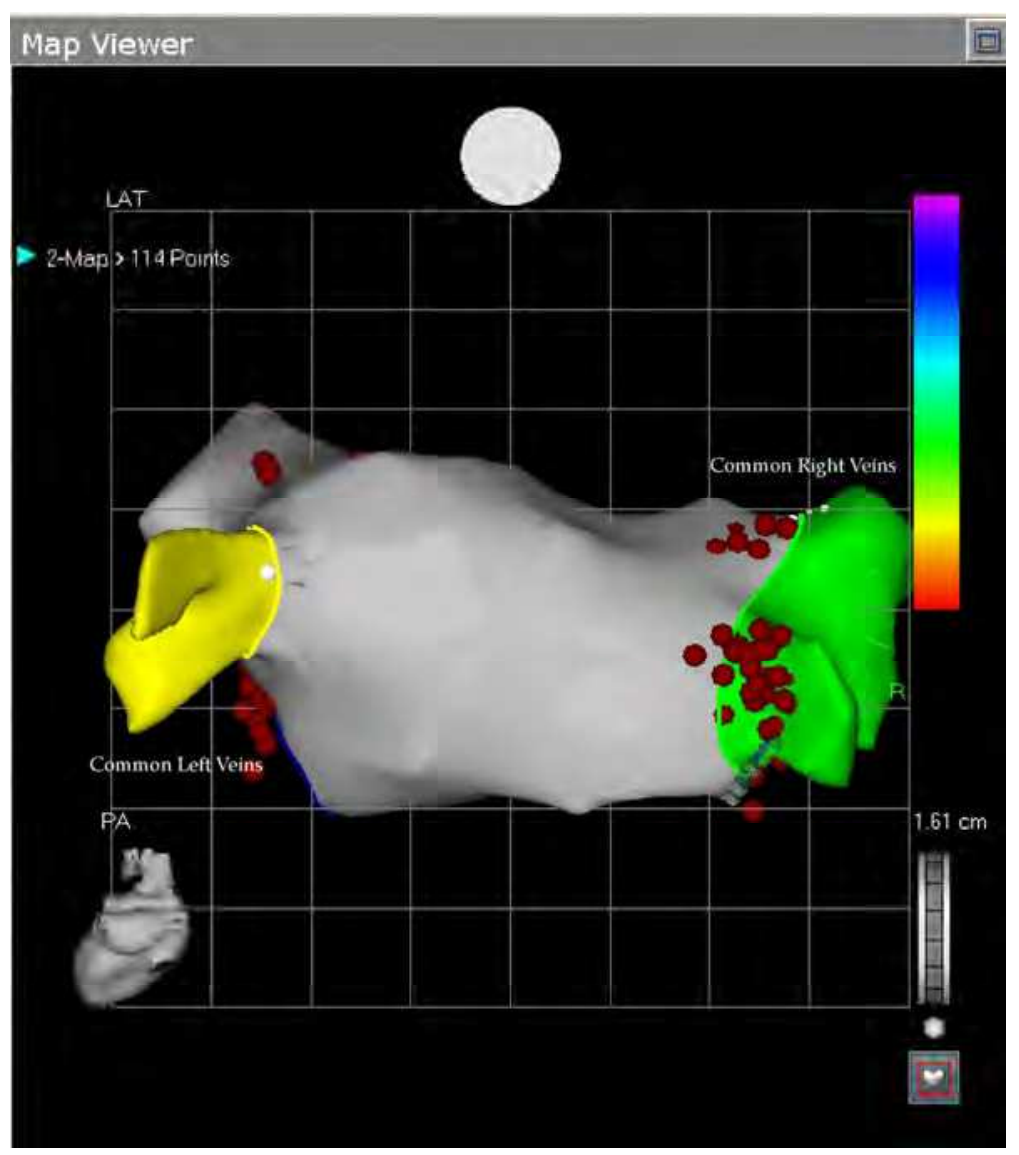

Fig. 6.7. The figure shows the posterior wall recoded with the fast map method. In the lower-posterior border of the right vein and on the junction point with the roofline additional application eliminated the activity and left the entire vein free of any electrical activity. The right vein different from the left, had multiple brunches and with common entrance into the left atrium. The anatomy was approved with the intra-cardiac echo recorded simultaneously with CARTO mapping. The posterior wall also free of electrical activity like in box-ablation (lines anterior to the veins completed with roofline and another line in the low atrium on the posterior wall).

\section{Ventricular tachycardia ablation}

A vast amount of information was accumulated during the last decades of the 20th Century supporting the superiority of implantable defibrillators (ICD) over any medical treatment in saving patients with high risk for sudden cardiac death (Ezekowitz JA et al, 2003). However, the defibrillator cannot guaranty the quality of life especially in patients with frequent ICD therapy. Moreover, patients may develop clusters of ventricular fibrillation, called VT storm. Some studies even suggest that repeated shock is associated with increased death rate 
(Exner DV et al, 2001; Poole JE et al, 2008; Daubert JP et al, 2008; van Rees JB et al, 2011). It is still not clarified if the presence of high number of VT or the shocks signals the imminent death. When both the ICD and adjuvant antiarrhythmic treatment (mainly Sotalol or Amiodarone) cannot prevent frequent recurrence of VT, the only option is the ablation (Sra J et al, 2001). The next step in the strategy is ablation before the storm or frequent recurrence of VT (Reddy V et al, 2007; Stevenson WG et al, 2008; Tung R et al, 2010; Kuck KH et al, 2010; Natale A et al, 2010). The main problem is that patients with structural heart disease have multiple VT foci, large scars with many possible reentry circles. For this reason, focal ablation may be only a temporary step. Occasionally, these patients with reduced left ventricular function may not tolerate hemodynamically the VT and focal ablation may not be feasible. To resolve this problem, scar ablation was suggested (Marchlinski FE et al, 2000; Sra J et al, 2001). The following 4 patients will exemplify these methods in different types of structural heart disease.

AA is a 60-year-old patient with coronary artery disease, large anterior myocardial infarction in the recent past, and ventricular tachycardia. A cardioverter-defibrillator was implanted. As the tachycardia reoccurred, amiodarone treatment was added. Amiodarone did not control the tachycardia and the symptomatic cardioverter-defibrillator therapy and the patient was frequently re-hospitalized.

For this reason, the patient was brought to the electrophysiology laboratory in purpose to study the ventricular tachycardia and to attempt an ablation procedure. The tachycardia was easily and reproducible induced with two premature beats. Although the tachycardia, on chronic amiodarone treatment, was relatively slow, the patient did not tolerate it hemodynamically. Propagation mapping was not applicable and the only option remained the scar/voltage mapping. Interestingly, the mapping revealed two scars, a large one and a small one with a small and narrow strip of myocardium between them. The small scar extended until the mitral annulus and no continuous myocardium surrounded it. The only reentry circuit for the slow tachycardia could be the large scar and by blocking the narrow myocardial strip between the scars necessarily will interfere with the current wave passage around the large scar, too.

The flowing pictures exemplify the scars and the ablation (Figures 7.1, 7.2 and 7.3)

The tachycardia has become not inducible after the ablation and during the 1 year followup since the ablation the patient was free of ICD therapies. As we can see, in this case a clear delineation of the reentry circle was revealed by the scar mapping without an intend to map the activation. Scar mapping is the option when the patient cannot tolerate the tachycardia (Marchlinski FE et al, 2000; Sra J et al, 2001). A narrow conduction tissue in the scar serves the tachycardia (Figure 7.2 and 7.3). The strategy is to block this tissue, however it is important to connect the scar to a non-conducting structure like valve annulus, otherwise the ablation will only increase the reentry circle and may render the tachycardia more incessant. In our patient the smaller scar was already connected to the mitral annulus (Figure 7.3) leaving the only possible reentry circle around the large scar and the target of the ablation the narrow myocardial strip in between them. This patient presents an ideal ablatable reentry circle. Eliminating the conduction only on a single possible pathway eliminates also the VT substrates and the patient continues to be without ICD therapy for one year. Identification of the channel was crucial in this procedure and is discussed in recent published literature (Arenal A et al, 2004; Hsia HH et al, 2006). 


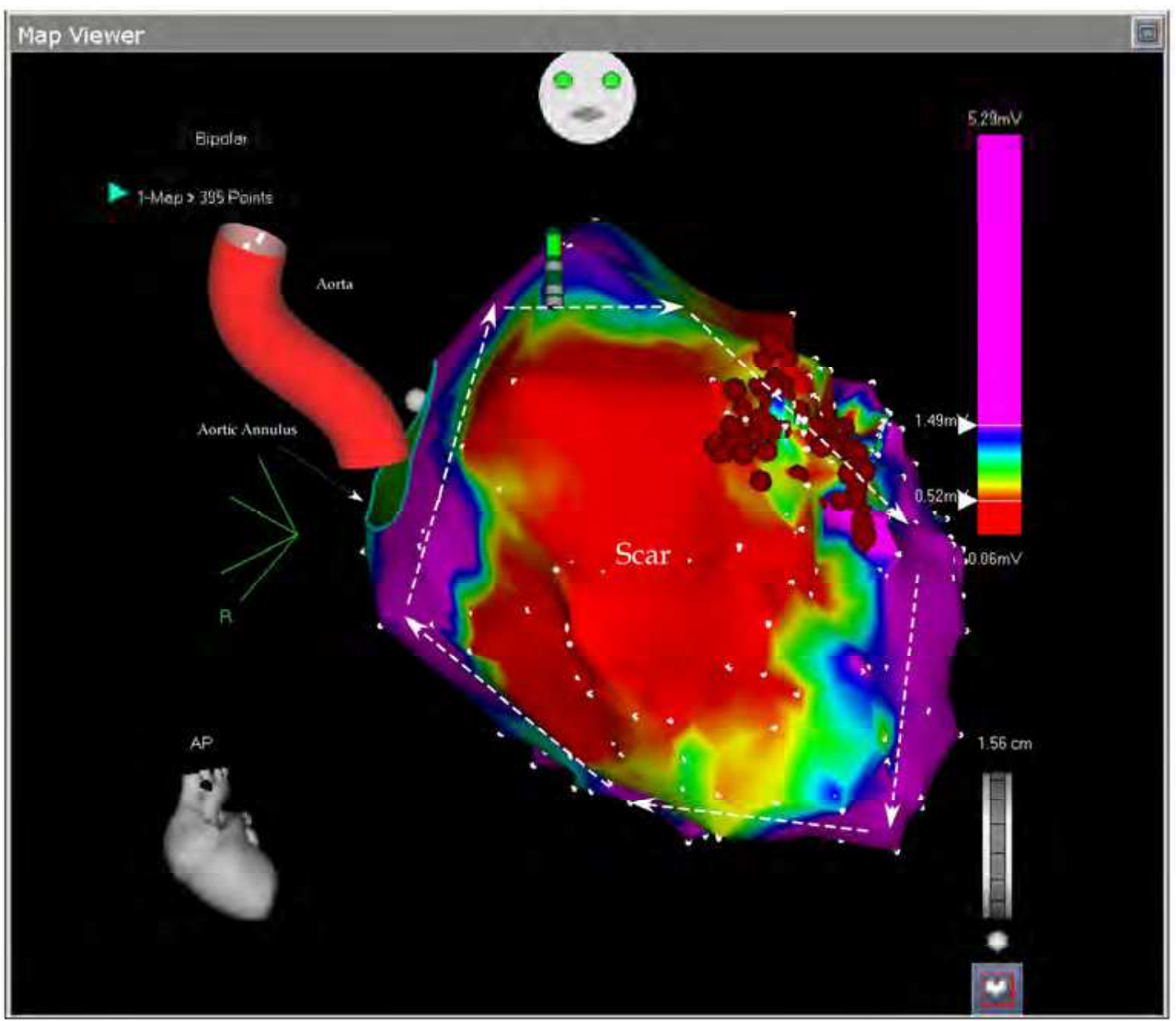

Fig. 7.1. The picture shows the antero-posterior projection of the enlarged left ventricle with a large scar on almost all the anterior wall. Any voltage bellow $0.5 \mathrm{mV}$ (red color) was considered scar and any voltage above $1.5 \mathrm{mV}$ were considered normal myocardium (purple color). In between them three transitional tissues are collared in yellow, green and blue. No tissue penetrated the scar and no central pathways could be mapped. The arrows show the large reentry cycle around the scar. Normal myocardium is around the scar and constitutes the reentry circle. The ablation points (red dots) block the isthmus between two scars (see Figure 6.2) 


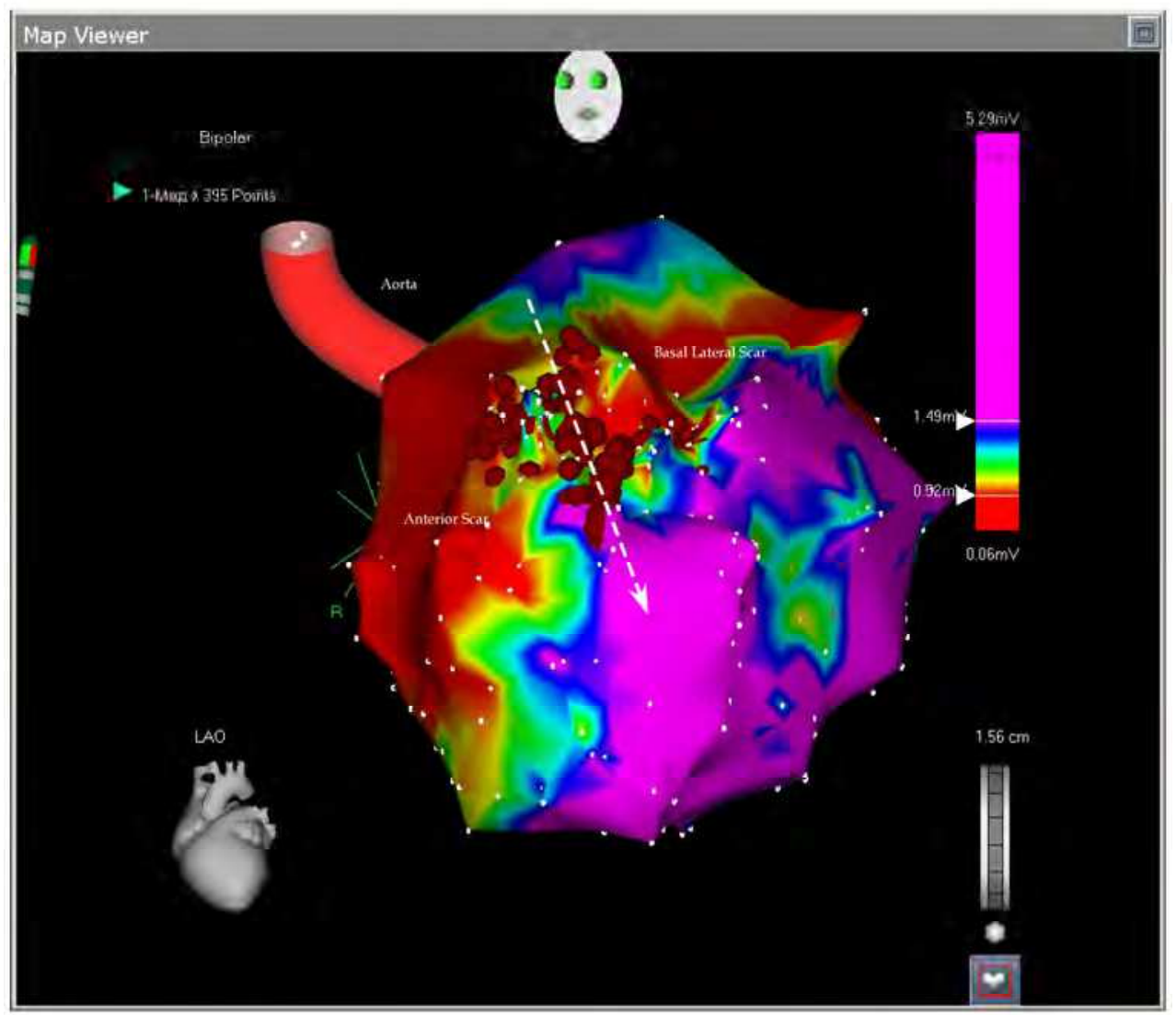

Fig. 7.2. The picture shows the antero-lateral projection of the left ventricle. In this voltage mapping two scars are evident: the large anterior scar and a smaller basal lateral scar. The scars delineate in between them a slowly conducting myocardial tissue called isthmus (arrow). The isthmus is blocked by the ablation points. As we will see in the next picture, the basal scar is extending until the mitral annulus the reason why the reentry could not be closed around it. 


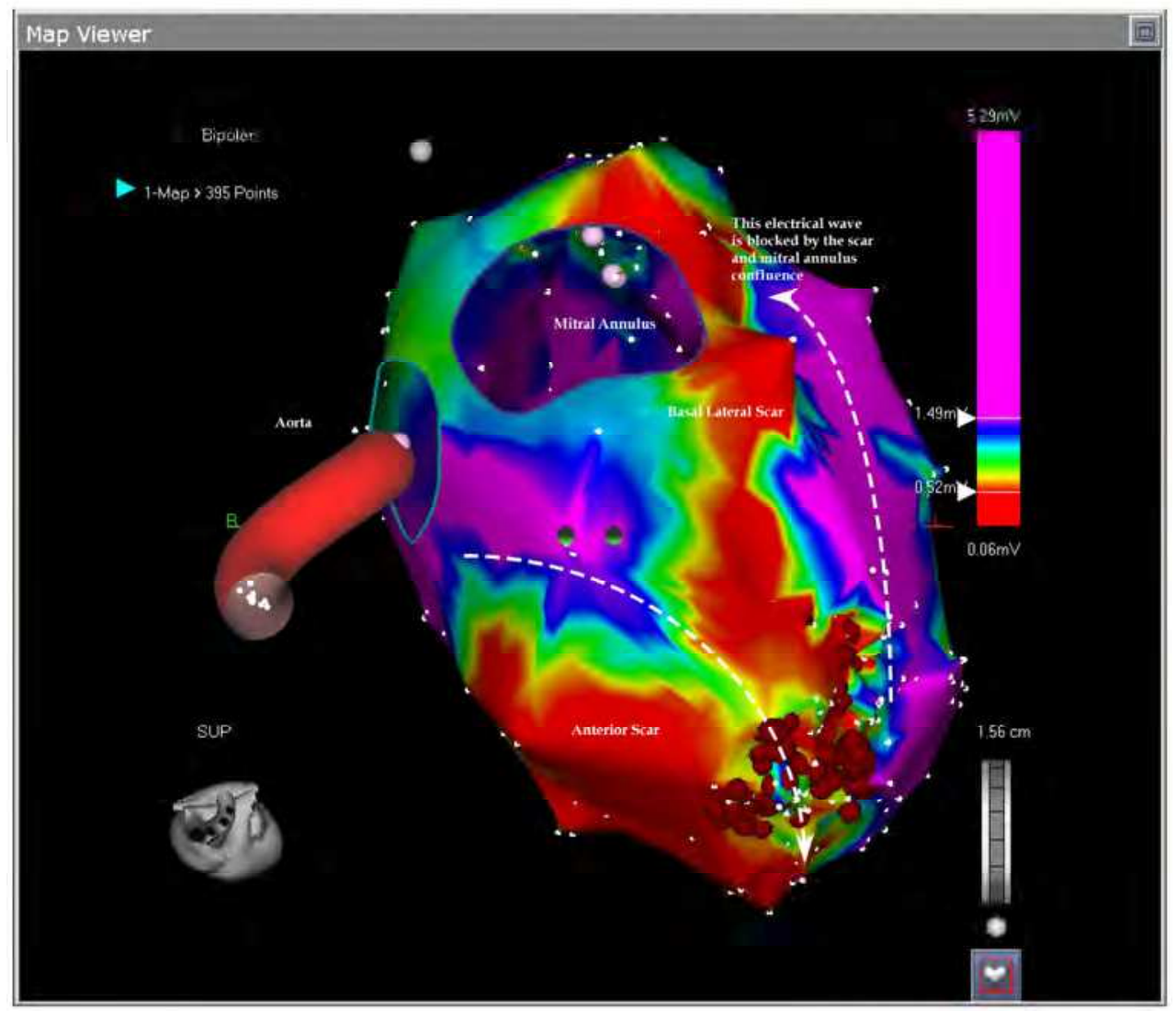

Fig. 7.3. This picture shows the superior projection of the left ventricle with the aortic and mitral annuli. The basal lateral scar is confluent with the mitral ring and this confluence prevents closure of the reentry around this lateral scar leaving only the anterior scar open to permit the reentry. The ablation blocked the isthmus leaving the tachycardia non inducible.

Scar ablation is an accepted approach to ablate ventricular tachycardia. Electromagnetic mapping is indispensable in delineating the scar and magnetic resonance imaging (MRI), three-dimensional computer topographies (CT) and positron emission topographies combined with CT (PET/CT) pictures may enhance it and makes possible evaluation of the exact transmural dispersion (Codreanu A et al, 2008; Dickfeld T et al, 2008, Tian J et al. 2010).

The second patient is AG; 61-year-old man with dilated cardiomyopathy, sustained ventricular tachycardia and was referred for CRTD (cardiac resynchronization therapydefibrillator) implantation. Interestingly, during the implantation, at the left lead pacing threshold measurement, the patient developed ventricular tachycardia. This suggested a tachycardia focus near the pacing area in the left basal posterior-lateral wall.

After the implantation he developed frequent episodes of VT not suppressed by adjuvant medical treatment with amiodarone and mexiletine (Figure 7.4). For this reason he was taken to the electrophysiology laboratory and the left ventricle was mapped during ventricular tachycardia (Figure 7.5 and 7.6). Only a partial mapping was needed (overall 27 points) and 
the tachycardia origin was located on the basal posterior wall (Figure 7.6), just like suggested by the induction during the implantation. After 4 radiofrequency application on this site the tachycardia terminated and has become non inducible. Of note, the ECG (Figure 7.4 and 7.5) suggested the basal posterior location of the origin and the QRS during the tachycardia had RBBB (Right Bundle Brunch Block), inferior and rightward axis (Figure 7.4 and 7.5).

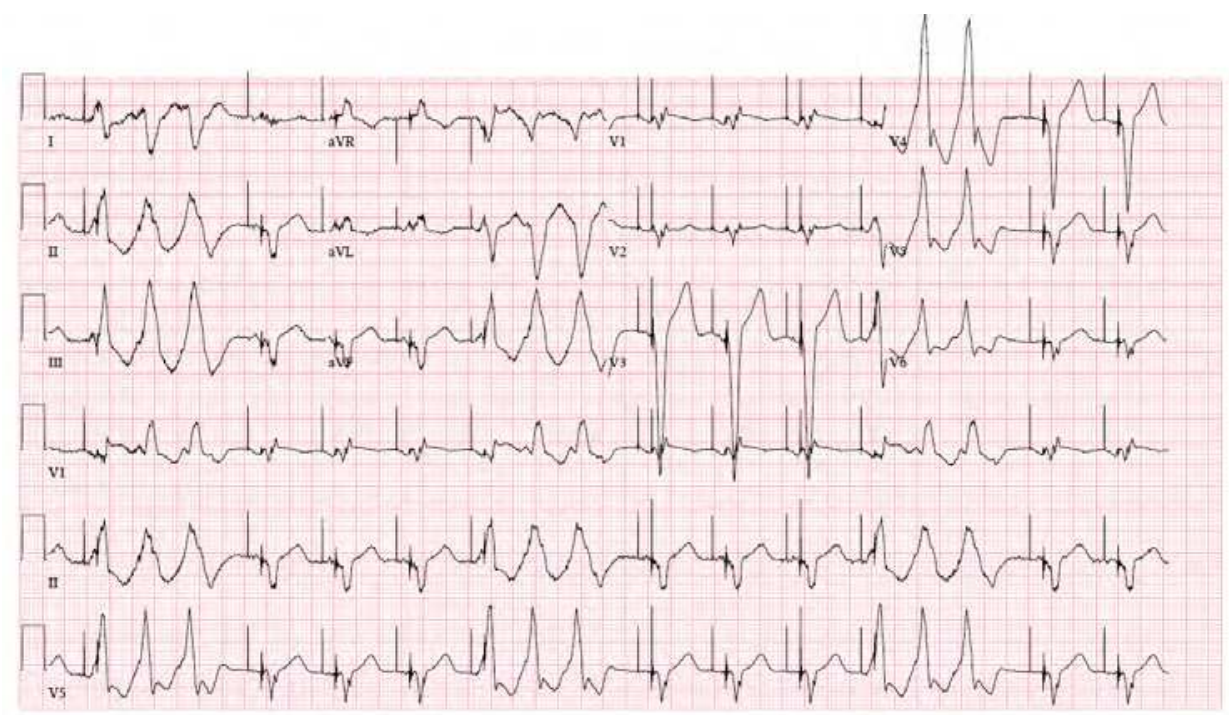

Fig. 7.4. The clinical VT in non-sustained form, but with the same morphology of RBBB, inferior and rightward axis

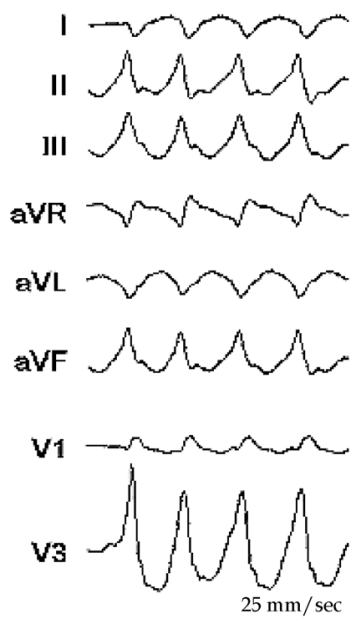

Fig. 7.5. The figure shows the ECG of the VT during the ablation. This VT had RBBB configuration and inferior and rightward axis. This configuration is suggesting a left ventricular VT with the origin in the basal area. 


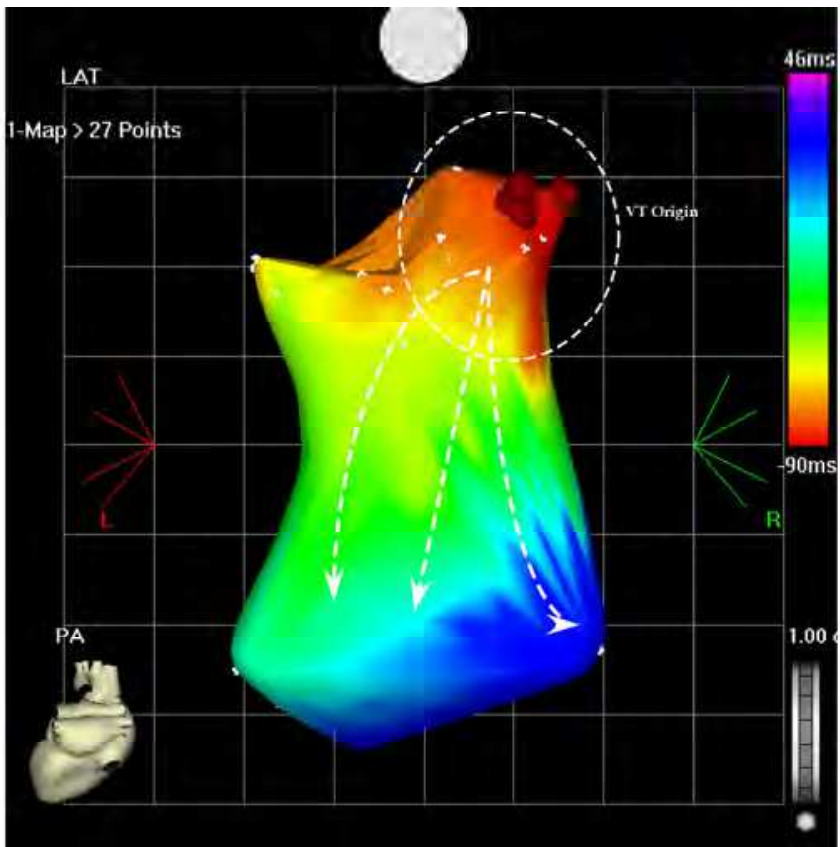

Fig. 7.6. The picture shows the potero-anterior projection of a part of the left ventricle during the VT. The earliest points are located on the basal posterior wall (red area) and the VT is propagated to the apical are as shown by the arrows (blue area). Ablation in this area terminated the VT and rendered it non-inducible.

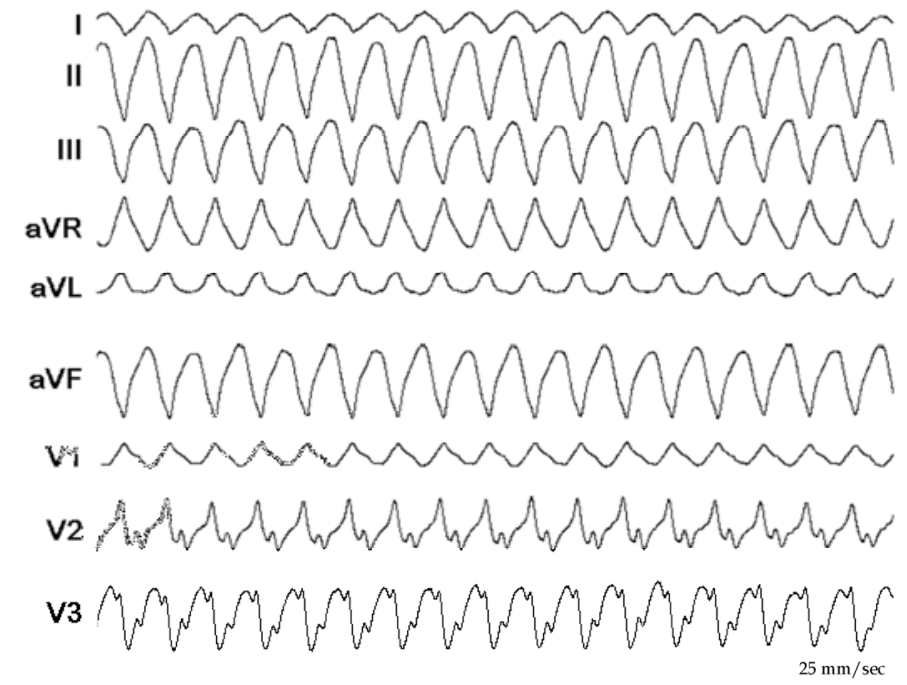

Fig. 7.7. The figure shows the ECG of the second VT during the ablation two weeks after the first one. The QRS has an RBBB configuration and superior axis. When compared with the 
first VT (Figure 7.5), the rightward axis is less expressed (L1 compared in the two ECGs, and AVL in the first ECG is negative and in the second is positive). There are also differences in the chest leads available (V3 is strongly positive in the first VT and clearly negative in the second VT). The rates of the VTs are similar.

Although the ablation was successful as exemplified by the previous pictures, the patient presented after two weeks with a second VT (Figure 7.7). He was taken again to the electrophysiology laboratory and the VT was mapped, again with CARTO (Figure 7.8). This time the VT had an RBBB configuration and superior axis! (Figure 7.7)

It was evident that the two VTs are not coming from the same area and again a limited map was completed (to avoid hemodynamic compromise during prolonged mapping). As Figure 7.8 exemplifies, the second VT originated from the apical septum. This are was ablated (Figure 7.9) and interestingly, after the ablation at the earliest point the tachycardia terminated, but was reinduced. This time the second ablation site at this procedure was more inferior, but after termination of the VT by the ablation, it has become noninducible.

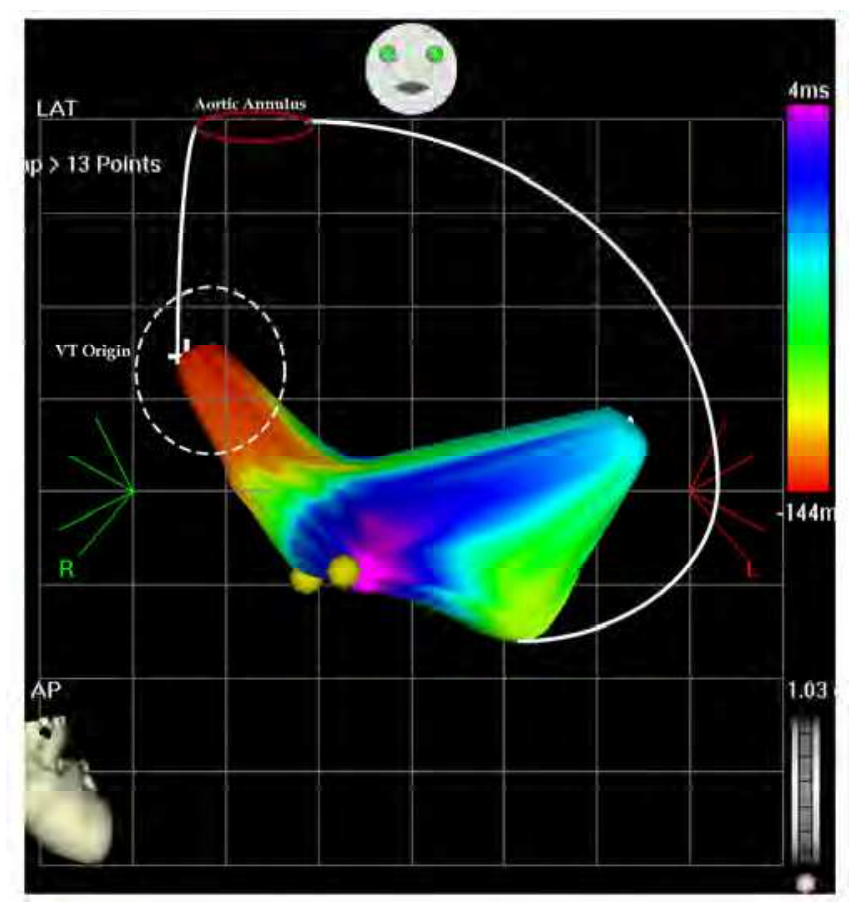

Fig. 7.8. The picture shows an antero-posterior projection of the left ventricular flow map during VT at the second ablation procedure. The left ventricular perimeter is shown with the white lines, including the aortic annulus. The earliest points are originating on the septal area and propagate in the anterior and posterior wall. There is collision on the inferior wall (pink color) and is tagged. The earliest points are $-144 \mathrm{msec}$ before the reference catheter in the right ventricle and the collision is $4 \mathrm{msec}$ after the reference catheter. 


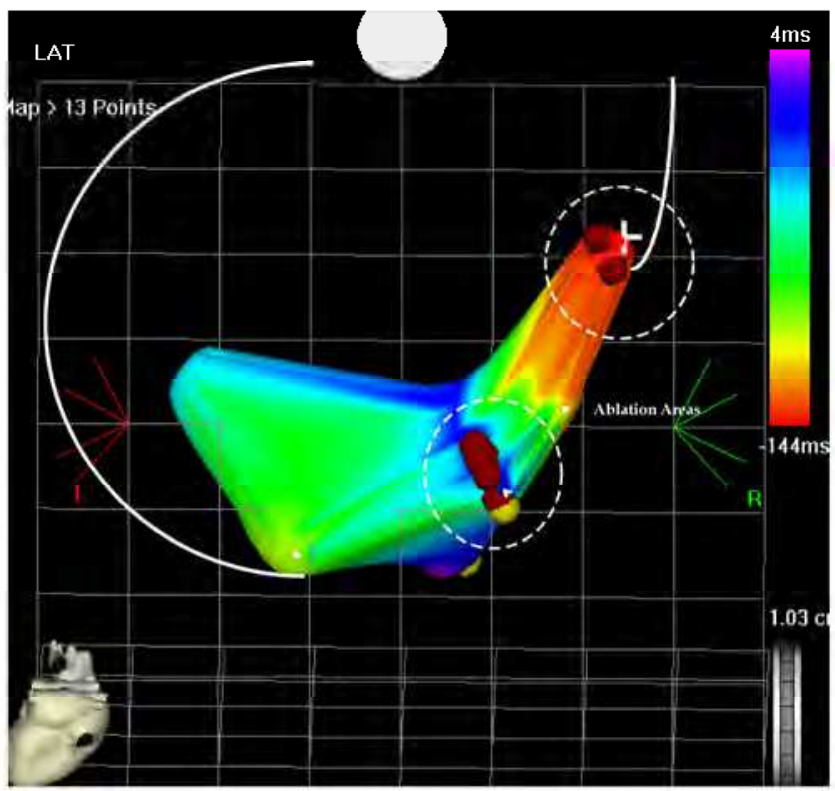

Fig. 7.9. The picture shows the flow map of the left ventricle in postero-anterior projection. Two areas had to be ablated to terminate the VT, first the higher area and earliest one was ablated than the second more inferior are which has become early (not shown) and finally terminated the VT and left it non-inducible.

At the end of the second ablation procedure a very fast VT (200 msec cycle length) was induced requiring DC shock termination (through the implanted ICD which was immediately activated). Two years after the second ablation the patient was free of any ICD therapy. Only rare non-sustained VT was stored by the ICD. In this patient we made several clinical decisions and observations during and around the ablation procedures:

1. The left ventricle mapping was not completed, was quickly achieved and culminated with ablation

2. Propagation mapping was done as this patient has dilated cardiomyopathy and no discrete scar can be mapped

3. Although the ICD was deactivated during the procedure to prevent early termination of the VT during the mapping, it was immediately activated with the induction of the rapid VT (200 msec cycle length- ventricular flutter)

4. The rapid VT-ventricular flutter was not clinical as was not recorded by the ICD during the long follow-up.

5. The proarrhythmic effect of biventricular pacing, well known from the current literature (Nayak HM et al, 2008; Gasparini M et al, 2008, Nordbeck P et al, 2010)

$\mathrm{CH}$ was a 59-year-old patient with a large anterior wall myocardial infarction, ventricular tachycardia and implantable defibrillator. 


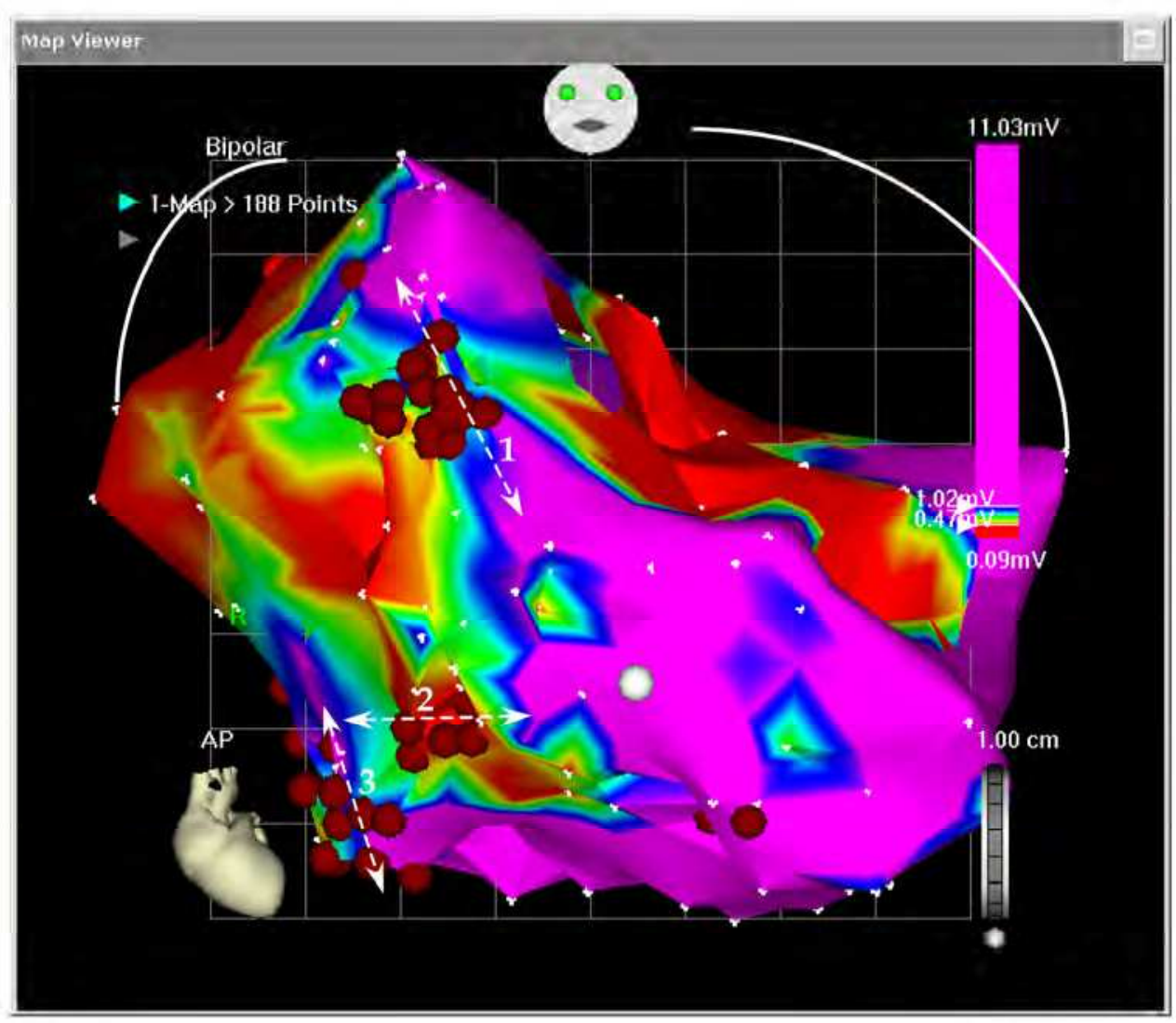

Fig. 7.10. The picture shows the extremely enlarged left ventricle, scar mapping and multiple isthmuses ablation ( 3 shown on this antero-posterior projection). All the procedure was completed during sinus rhythm, without ventricular pacing. The defibrillator was deactivated during the procedure.

The defibrillator was upgraded to CRTD. Two years after the upgrading, he presented with "VT storm" (more than 150 episodes of VT, majority treated with overdrive pacing and two of them with ICD shock). As medical treatment was not effective and the tachycardia has become resistant to overdrive pacing (including pacing from the RV lead, LV lead and biventricular), he was taken to the electrophysiology laboratory for catheter ablation. It was understood that no mapping during the VT can be completed because the hemodynamic imbalance. Scar mapping was attempted. The left ventricle was extremely enlarged and no catheter was available to complete to basal area mapping. After the ablation the VT frequency was significantly reduced, but not completely abolished and the patient had ventricular assist device implantation, but not survived until appropriate donor heart was available for him.

$\mathrm{BN}$ is a 75 year-old-man with a history of a large anterior infarction at the end of 1980's. He was treated with intravenous Streptokinase and despite apparent reperfusion the laboratory 
tests suggested a large infarction. In the early 1990's he developed aborted sudden cardiac death and a defibrillator was implanted. Occasionally, he had successfully treated episodes of ventricular tachycardia and was resolved with adjuvant amiodarone treatment. In 2008 the defibrillator was upgraded to cardiac resynchronization therapy-defibrillator (CRT-D). Recently he was admitted with incessant tachycardia with a rate between 135-140 beats per minute with relative hemodynamic stability. No medical treatment could suppress the tachycardia, including amiodarone reloading, additional mexiletine, beta-blockers and carvedilol. A coronary angiogram revealed no new coronary lesions and no target for revascularization. As the tachycardia was still incessant, the patient was taken to the electrophysiology laboratory for an ablation attempt. The left ventricle was approached through the aortic valve and the left ventricle was mapped using the fast map technique. The patient was all this time in his slow ventricular tachycardia. As evident in Figure 7.11, the left ventricle is enlarged with a large apical aneurysm and a large scar on the anterolateral wall. The origin of the tachycardia was in the apical area at the border of the large scar (Figure 7.11). Ablation in this site terminated the tachycardia and was returned to the Cardiology Ward in sinus rhythm.

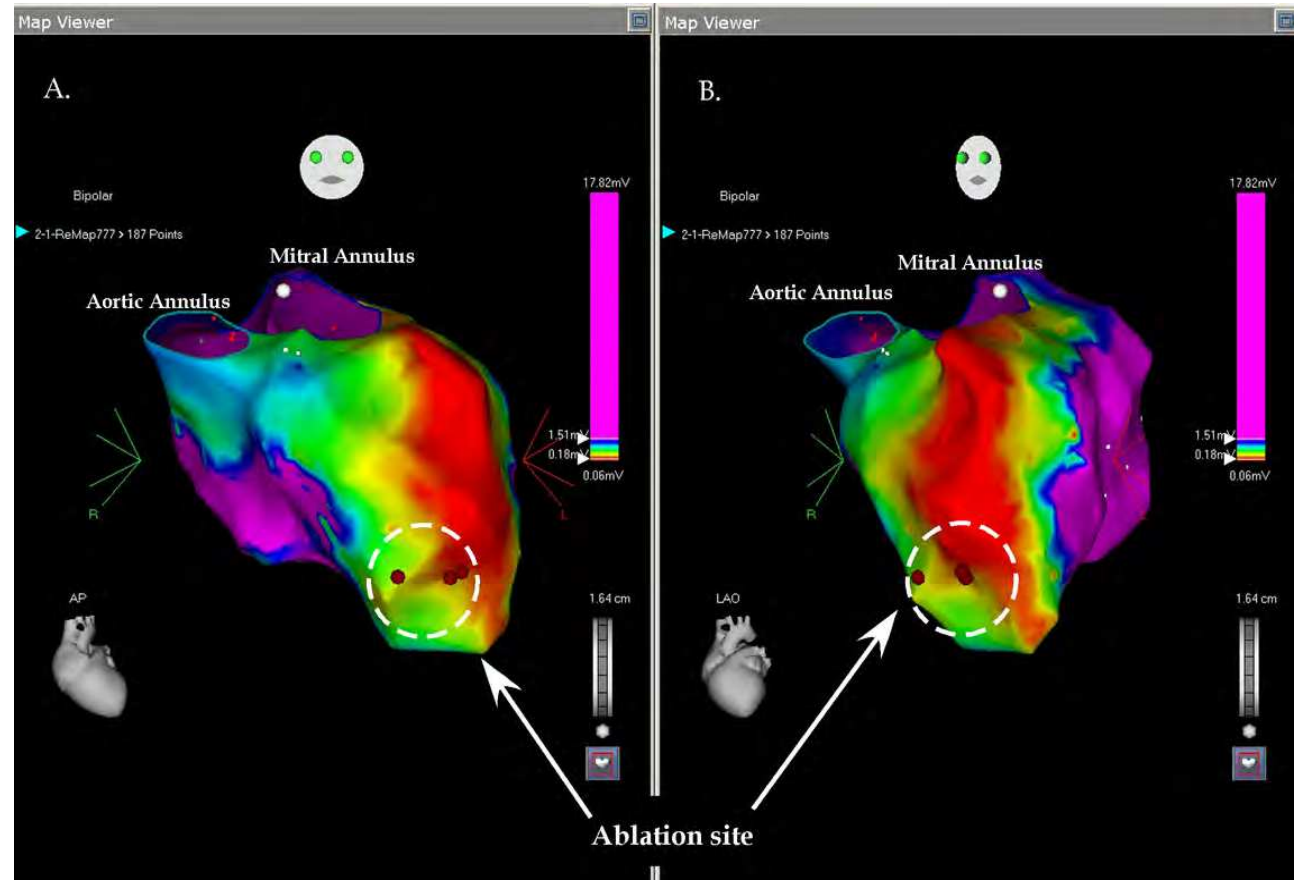

Fig. 7.11. The picture shows the voltage mapping of the left ventricle in two projections: A. antero-posterior; B. left anterior oblique; the ventricle is enlarged with a large apical aneurysm and a large antero-lateral scar. The ablation site is shown in both projections and the ablation was completed during incessant ventricular tachycardia (135 BPM) and propagation mapping. With the two lateral applications the tachycardia terminated spontaneously. 
Although the tachycardia was not anymore incessant, the patient still had episodes of tachycardia at a faster rate (150-160 beats per minute). As this tachycardia was not tolerated, he was returned to the electrophysiology laboratory for a "scar ablation". This time the tachycardia was not induced and the mapping was completed in sinus rhythm (paced rhythm). Using slightly different definitions (scar in the first mapping was defined as $<0.18$ $\mathrm{mV}$ and during the second mapping as $<0.54 \mathrm{mV}$ ), a large golf of myocardial tissue was revealed in the anterior basal area (Figure 7.12). This area was isolated from the surrounding normal tissue and the ablation area was continued until the mitral annulus to avoid any possible large reentry around the whole scar. Although the endocardial surface was completely blocked, the tachycardia was still inducible with impression of multiple breakthrough points suggesting epicardial origin. However, no real mapping could be completed because the hemodynamic instability during the VT. For this reason, he was scheduled for an epicardial ablation. During the epicardial mapping the origin of the VT was on the apical area and wide area ablation terminated the tachycardia. This epicardial site was almost the same with the successful site during the first mapping. During 3 months follow up the defibrillator recorded and stored only 4 episodes of VT successfully treated with overdrive pacing and not recalled by the patient. He continued the combination of amiodarone and carvedilol treatment. This patient also exemplifies the presence of multiple VT foci in a patient with ischemic cardiomyopathy and a large post myocardial infarction scar.

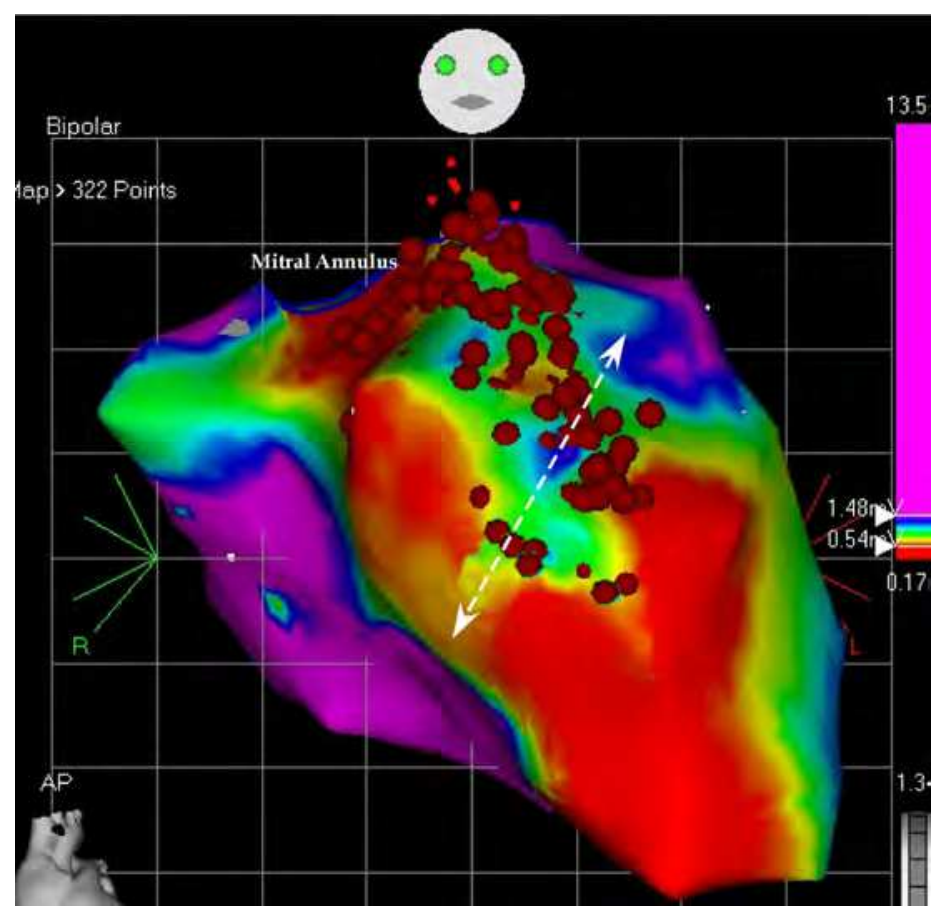

Fig. 7.12. The picture shows the mapping during the second ablation attempt. This is an antero-posterior projection of the left ventricular voltage mapping. The normal tissue was defined as $>1.5 \mathrm{mV}$ (like in Figure 6.11), but the scar was defined as $<0.5 \mathrm{mV}$. A large invagination of myocardium into the basal scar was revealed and ablated (see text). 
In this patient, with poor left ventricular function and resynchronization therapy, a combined endocardial focal ablation, scar ablation and finally epicardial ablation completed the procedure and achieved an acceptable clinical outcome. The electro-anatomic mapping exemplifies the complexity of the ablation in this patient, and it was possible only using this advanced mapping.

Four patients were presented, each one with a different condition and different mapping. The first patient had a well-defined scar with a clear narrow strip of myocardium dividing it into a large scar and a smaller basal scar limited by the mitral annulus. The second patient has dilated cardiomyopathy without discrete scar and two different foci ablated in two consecutive procedures. The third patient had an extreme ischemic cardiomyopathy, with uncontrollable ventricular tachycardia storm and labile hemodynamic condition. Only scar ablation was possible, because the extremely dilated left ventricle. The fours patient had an enlarged left ventricle, with a large apical aneurysm. The same patient has endocardial focal ablation, scar ablation and finally epicardial ablation.

\section{Theoretical aspects}

As mentioned in the introduction, first DC shock ablations than RF ablation of solitary pathways in the AV Node or outside it is practiced in clinical electrophysiology. However, DC was used for the first AV Nodal ablation, well-defined origin of WPW and ventricular tachycardia foci. Radiofrequency replaced the DC shock. During 2-3 years first the AV Nodal and AV pathways were ablated. Subsequently, idiopathic VT foci and atrial flutter and focal tachycardia were ablated. In the early 1990's, ventricular tachycardia in structural heart disease, atrial fibrillation and idiopathic ventricular fibrillation were not considered candidates for ablation. Electro-anatomic mapping open the possibility to ablate this complex arrhythmia foci. (Exception was atrial fibrillation where first focal ablation than point ablation guided by special catheters- lasso- preceded the electro-anatomic mapping).

\subsection{Atrial tachycardia ablation}

In large branching scar, the ablation requires electroanatomic mapping. Patients after corrective surgery of congenital heart disease may develop large scars in the atrium and frequently develop incisional reentry tachycardia. As early as in 2001, several institutions reported small groups or case reports describing the use of electroanatomic mapping (Leonelli FM et al, 2001; Peichl P et al, 2003). Before the use of this mapping, electrophysiological definition of the slow isthmus, called central pathway, was needed. This was a long procedure with limited success. The electro-anatomic mapping delineates the scar, and delineates the isthmus in between scars or in the scar itself. Blocking these pathways, or as occasional called, channels, will prevent induction or spontaneous recurrence of the tachycardia. Interestingly, the number of publication describing the use of electroanatomic mapping for ablation of focal tachycardia ablation is much larger (Kottkamp H et al, 1997; Marchlinski FE et al, 1998; Cummings RM et al, 2008). There is also ample of information on the use of this mapping in the ablation of different left atrial tachycardias (Iwai S et al, 2002; Marrouche NF et al, 2002; Kistler PM et al, 2003; Dong J et al, 2005). Left atrial tachycardias may originate on the septum, along the mitral annulus and from the pulmonary veins. Correct mapping may localize the origin and ensure successful ablation.

Two arrhythmias were extensively discussed in the literature: atrial fibrillation ablation and ablation of ventricular tachycardia in patients with structural heart disease. 


\subsection{Atrial fibrillation ablation}

After the description of the pulmonary vein as trigger in atrial fibrillation, ablation was attempted, first focal, than pulmonary vein isolation (Haissaguerre $\mathrm{M}$ et al, 1998). A special catheter was developed- the lasso catheter- to permit mapping of the pulmonary vein osteum and to localize the pathway connecting electrically the vein with the left atrium. This site was ablated and pacing from the coronary sinus could prove the electrical disconnection of the veins (Takahashi $Y$ et al, 2007). This treatment was indicated for patients with paroxysmal atrial fibrillation and not for the other forms of chronic atrial fibrillation, like persistent and permanent. Atrial fibrillation ablation based on electro-anatomic mapping has become an accepted alternative to the pulmonary vein disconnection (Pappone $\mathrm{C}$ et al 1999; Pappone C et al, 2000; Pappone C et al 2004; Oral H et al 2006, pappone et al, 2006). Developed at the beginning of this century, this approach offered already at the beginning of its implementation, a possible ablation also for persistent atrial fibrillation and even for long standing persistent type (more then 1 year). The pulmonary vein isolation is achieved by circle ablation in the antrum of the veins. Line ablations in the roof and in the mitral isthmus (between the mitral annulus and the left lower pulmonary vein) completes the procedure and are necessary to avoid left atrial flutter/tachycardia around the ablation rings in the pulmonary vein antrum. One first advantage of the left atrial ablation is the sparing of the vein and by this to reduce to minimum the possible damage to the vessel. This damage may result in pulmonary vein stenosis/occlusion, pulmonary hypertension and symptomatic shortness of breath. The correct and exact reconstruction of the left atrium and its appendages is a prerequisite not only for successful isolation of the pulmonary veins, but also for preventing the above-mentioned damage. Following the original introduction of the electro-anatomic approach to atrial fibrillation ablation, this method was compared with the original pulmonary vein disconnection and both the acute success and the recurrence rate after 1 year was in advantage of the left atrial ablation (Oral $\mathrm{H}$ et al, 2003). Moreover, the method was evaluated in patients with long-persistent atrial fibrillation and a significantly higher number of patient in the ablation group was in sinus rhythm after 1 year-77\% versus 53\% (Oral $\mathrm{H}$ et al, 2006a). A large percent of the control group moved to the ablation group and the symptomatic improvement was significantly higher in the ablation group. An additional approach to atrial fibrillation ablation was targeted to complex atrial electrograms. This method is accepted as adjuvant to the left atrial ablation. Finally, even if the first method is use to disconnect the pulmonary veins, the procedure is escalated and elements of the second and third procedure are added (Oral H et al, 2006b; Takahashi $\mathrm{Y}$ et al, 2007). Although, we are still not at the end of the way in the development of atrial fibrillation ablation methods, the place of the electroanatomic mapping is well established. The most complex ablation is probably that of ventricular tachycardia in patients with structural heart disease.

\subsection{Ventricular tachycardia ablation}

Ventricular tachycardia ablation is going back to 1983 when DC shock was delivered to the ablation site (Hartzler GO, 1983). Soon after the presentation of ablation using radiofrequency energy, it was applied to patients with idiopathic ventricular tachycardia (Kuck KH et al, 1991; Klein LS et al, 1992) and subsequently to ventricular tachycardia in structural heart disease (Morady $\mathrm{F}$ et al, 1993). Different methods of pacing helped to localize a critical area in the tachycardia circle or focus pending on the type of heart disease. Although this method was successful, the procedure was prolonged, required a long time to 
be in ventricular tachycardia and the recurrence rate or new tachycardias generation were high. It has become accepted as an adjuvant to other treatments and focused to the tachycardia causing repeated defibrillator therapy, ventricular tachycardia storm or intolerable shock therapy. The electroanatomic mapping opened to possibility to delineate the scar and reveal any narrow strips of myocardium bridging through the scar. These strips are targeted in the ablation and they are necessary parts of the tachycardia circle. In patients with tolerated tachycardia, the propagation map points to the tachycardia origin. This origin may be the exit point of the reentry circle or the other non-reentry focus (like in patients with dilated or hypertrophic cardiomyopathy). The ablation may be targeted to this early point. There is no need to hold the patient in prolonged tachycardia and no need for the pacing techniques. Moreover, in patients with non-tolerated tachycardia the scar is mapped and is isolated and connected to the valve annulus. Ablation, before defibrillation implantation, may reduce significantly the defibrillator therapy, when compared to nonablation control group. This approach was called SMASH-VT (Reddy V et al, 2007, Kuck KH et al, 2010). Finally, endocardial ablation may be completed with epicardial ablation (Tedrow U \& Stevenson WG, 2009; Sacher F et al, 2010). In patients with post myocardial infarction scars, most of the tachycardia reentry circle is endocardial, but in patients with dilated cardiomyopathy it may be epicardial (Nakahara S et al, 2010).

\subsection{Future ablations}

There are several other ablation targets recently added to the electrophysiology treatment armamentarium. The first arrhythmia is the idiopathic ventricular fibrillation. Patient with idiopathic ventricular fibrillation may need daily shock therapies and no medical treatment can suppress it. For these patients ablation of the initiating beats origin may reduce the number of treatments needed. These sites are characterized by high density of Purkinje fibers. Clinically, fascicular spikes may be recorded at the successful site in the ventricle (Knecht S et al, 2009; Natale A et al, 2010). If this approach will be applicable in patients with aborted sudden cardiac death and structural heart disease is still on evaluation. The second group with possible future application of electro-anatomic mapping is in patients with Brugada Syndrome. Epicardial fractionated electrograms in the RV outflow may be targeted and after the ablation, the ECG normalizes (Nademanee K et al, 2011). Occasionally, the site may be approached from the endocardium. Of note, the ventricular wall in the RV outflow is relatively thin.

If these two ablations will be implemented in routine practice, the future years will let us know.

\section{Conclusions}

Complex ablation has become routine in the clinical electrophysiology. Although these arrhythmias originally were approached with classical electrophysiology methods, the electroanatomic mapping simplified them and opened these ablations before rapidly increasing number of electrophysiology centers.

\section{References}

Arenal A, del Castillo S, Gonzalez-Torrecilla E, Atienza F, Ortiz M, Jimenez J, Puchol A, Garrcia J 7 Almedral J. (2004). Tachycardia-related channel in the scar tissue in 
patients wuth sustained monomorphic ventricular tachycardia: Influence of the voltage scar definition. Circulation Vol. 110:2568-2574

Ben Haim SA, Gepstein L, Hayam G, Ben David J \& Josephson MM. (1996a). A new nonfluoroscopic Electroanatomic mapping system. Pacing Clin Electroanatomic mapping system. Pacing Clin Electrophysiol Vol. 19:709

Ben-Haim SA, Osadchy D, Schuster I, Gepstein L, Hayam G \& Josephson MM. (1996b). Nonfluoropscopic, in vivo navigation and mapping technology. Nature Med Vol. 2:1393-1395

Codreanu A, Odille F, Aliot E, Marie PY, Angnin-Poull I, Andonache M, Mandry D, Djaballah W, Regent D, Felblinger J \& de Chillou C. (2008). Electroanatomic characterization of post-infarction scars. Comparison with 3-dimensional myocardial scar reconstruction based on magnetic resonance imaging. J Am Coll Cardiol Vol. 52:839-42

Cosio FG, Lopez-Gil M, Goicolea A, Arribas F \& Barroso JL. (1993). Radiofrequency ablation of the inferior vena cava-tricuspid valve isthmus in common atrial flutter. Am J Cardiol Vol. 71:705-709

Cummings RM, Mahle WT, Stieper MJ, Cambell RM, Costelo L, Balfour V, Burchfeld A, Frias PA. (2008). Outcome following electroanatomic mapping and ablation for the treatment of ectopic tachycardia in the pediatric population. Pediatr Cardiol Vol. 29:393-397

Daubert JP, Zareba W, Cannom DS, McNit S, Rosero SZ, Wang P, Schuger C, Steinberg JS, Higgins SL Wilber DJ, Klein H, Andrews ML, Hall J, Moss AJ \& the MADIT II investigators. (2008). Inappropriate implantable cardioverter defibrillator shock in MADIT II. Frequency, mechanism, predictors, and survival impact. J Am Coll Cardiol Vol. 51:1357-1365

Dickfeld T, Lei P, Dilsizian V, Jeudy J, Dong J, Voudouris A, Peters R, Saba M, Shekhar R \& Shorofsky S. (2008). Integration of three-dimensional scar maps for ventricular tachycardia ablation with positron emission tomography-computer tomography. JACC: Cardiovascular Imaging Vol. 1:73-82

Dong J, Zrenner B, Schreieck J, Deisenhofer I, Karch M, Schneider M, Von Bary C, Weyerbrock S, Yin Y \& Schmitt C. (2005). Catheter ablation of left focal atrial tachycardia guided by electroanatomic mapping and new insights into interatrial electrical conduction. Heart Rhythm Vol. 2:578-591

Ehrlich JR, Cha TJ, Zhang L, Chartier D, Melnyk P, Hohnloser S \& Nattel S. (2003). Cellular electrophysiology of canine pulmonary vein cardiomyocytes: action potential and ionic current properties. J Physiol Vol. 551:801-813

ExnerDV, Pinski SI, Wyse G, Renftoe EG, Follman D, Gold M, Beckman KJ, Coromilas J, Lancester S, Hallstrom AP \& the AVID investigators. (2001). Electrical storm presages nonsudden death: The Antiarrhythmic Versus Implantable Defibrillators (AVID) Trial. Circulation Vol. 103:2066-2071

Ezekowitz JA, Amstrong PW \& McAlister FA. (2003). Implantable cardioverter defobrillators in primary and secondary prevention: a systematic review of randomized trials. Ann Intern Med Vol. 138:445-452

Feld GK, Fleck P, Chen PS, Boyce K, Bahnson TD, Stein JB, Calisi CM \& Ibarra M. (1992) Radiofrequency catheter ablation for the treatment of human type 1 atrial flutter. Circulation Vol. 86:1233-1240 
Gasparini M, Lunati M, Landolina M, Santini M, Padaletti L, Perego G, Vincenti A, Curnis A, Carboni A, Denaro A, Spotti A, Grammatico A, Regoli F, Boriani G \& on behalph of the InSync ICD Italian Registry Investigators. (2008). Electrical storm in patients with biventricular implantable cardioverter defibrillator: incidence, predictors, and prognostic implications. Am Heart J Vol. 156:847-854

Gepstein L, Hayam G, Josephson ME \& Ben-Haim SA. (1996). A new method for cardiovolumetric measurement based on nonfluoroscopic electrophysiological electroanatomic. Pacing Clin Electrophysiol Vol. 19:724

Gepstein L, Hayam G \& Ben Haim SA. (1997). A novel model for nonfluoroscopic catheterbased electroanatomic mapping of the heart: in vitro and in vivo accuracy results. Circulation Vol. 95:1611-1622

Gepstein L, Goldin A, Lessick J, Hayam G, Shpun S, Schwartz Y, Hakim G, Shofty Turgeman A. Kirshenbaum D \& Ben Haim SA. (1998). Electromechanical characterization of chronic myocardial infarction in the canine coronary occlusion model. Circulation Vol. 98:2055-2064

Hassaguerre M, Shoda M, Jais P, Nogami A, Shah DC, Kautzner J, Arentz TKalushe D, Lamaison D, Griffith M, Cruz F, de Paola A, Gaita F, Hicini M, Garrigue S, Macle L, Weerasooriya R \& Clementi J. (2002). Mapping and ablation of idiopathic ventricular fibrillation. Circulation Vol. 106:962-967

Haissaguerre M, Jais P, Shah DC, Takahashi A, Hocini M, Quinou G, Garrigue S, Le Mouroux A, Le Metayer P \& Clementy J. (1998). Spontaneous initiation of atrial fibrillation by ectopic beats originating in the pulmonary veins. $N$ Engl J Med Vol. 339:659-666

Hartzler GO. (1983). Electrode catheter ablation of refractory focal ventricular tachycardia. J Am Coll Cardiol Vol. 2:1107-1113

Hayam G, Gepstein L \& Ben-Haym. SA. (1996). Accuracy of the In Vivo Deternination of location using non fluoroscopic electroanatoamical mapping system. Pacing Clin Electrophysiol Vol. 19:712

Hsia HH, Lin D, Sayer WH, Callans DJ \& Marchlinski FE. (2006). Anatomic characteristics of endocardial substrate for hemodynamic stable reentrant ventricular tachycardia: identification of endocardial conducting channels. Heart Rhythm Vol. 3:503-512

Iwai S, Markowitz SM, Stein KM, Mittal S, Slotwiner DJ, Das MK, Cohen JD, Hao SC \& Lerman BB. (2002). Response to adenosine differentiates focal from macroreentrant atrial tachycardia. Validation using three-dimensional electroanatomic mapping. Circulation Vol. 106:2793-2799

Jackman WM, Beckman KJ, NcClelland JH, Wang X, Friday KJ, Roman CA, Moulton KP, Twidale N, Hazlitt HA, Prior MI, Oren J, Overholt ED, Lazzara R. (1992). Treatment of supraventricular tachycardia due to atrioventricular nodal reentry, by radiofrequency catheter ablation of slow-pathway conduction. N Engl J Med Vol. 327:313-318

Kistler PM, Saders PB, Hussin A, Morton JB, Vohra JK, Sparks PB \& Kalman JM. (2003). Focal atrial tachycardia arising from the mitral annulus. Eelctrocardiographic and electrophysiologic characterization. J Am Coll Cardiol Vol. 41:2212-2219

Klein LS, Shih HT, Hackett K, Zipes DP \& Miles WM. (1992). Radiofrequency catheter ablation of ventricular tachycardia in patients without structural heart disease. Circulation Vol. 85:1666-1674 
Knecht S, Sacher F, Wright M, Hocini M, Nogami A, Arentz T, Petit B, Frank R, De Chillou C, Lamison D, Farre J, Lavergne L, Weerasooriya R, Cauchemez B, Lellouche N, Derval N, Narayan SM, Jais P \& Clementy J, Haissaguerre M. (2009). Long-term follow-up of idiopathic ventricular fibrillation ablation: a multicenter study. $\mathrm{J} \mathrm{Am}$ Coll Cardiol Vol. 54:522-528

Kottkamp H, Hindricks G, Breithardt G \& Borggrefe M. (1997). Three-dimentional electromagnetic catheter technology: Elecroanatomical mapping of the right atrium and ablation of ectopic tachycardia. Pacing Clin Electrophysiol Vol. 8:1332-1337

Kuck KH, Schluter M, Geiger M \& Siebels J. (1991). Successful catheter ablation of human ventricular tachycardia with radiofrequency current guided by an endocardial map of the area of slow conduction. Pacing Clin Electrophysiol Vol. 14:1060-1071

Kuck KH, Schamann A, Eckhardt L, Willems S, Ventura R, Delacretaz E, Pitcschner HF, Kautzner J, Schumacher B, Hansen PS \& for the VTACH study group. (2010). Catheter ablation of stable ventricular tachycardia before defibrillator implantation in patients with coronary artery disease (VTACH): a multicenter randomized controlled trial. Lancet Vol. 375:31-40

Kumagai K, Muraoka S, Mitsutake C, Takashima H \& Nakashima H. (2007). A new approach for complete isolation of the posterior left atrium including pulmonary veins for atrial fibrillation. J Cardiovasc Electrophysiol Vol. 18:1047-1052

Lee MA, Morady F, Kadish A, Schamp DJ, Chin MC, Scheinman MM, Griffin JC, Pederson D, Goldberger J, Calkins H, deBuitleir M, Kou WH, Rosenheck S, Sousa J \& Langberg J. (1991). Catheter modification of the atrioventricular junction with radiofrequency energy for control of atrioventricular nodal reentry tachycardia. Circulation Vol. 83:827-835

Leonelli FM, Tomassoni G, Richey M \& Natale A. (2001). Ablation of incisional atrial tachycardias using three-dimensional nonfluoroscopic mapping system. Pacing Clin Electrophysiol Vol. 24:1653-1659

Marchlinski F, Callans D, Gottlieb C, Rodriguez E, Coyne R \& Kleinman D. (1998). Magnetic electroanatomic mapping for ablation of focal atrial tachycardias. Pacing Clin Electrophysiol Vol. 21:1621-1635

Marchlinski FE, Callans DJ, Gottlieb CD \& Zado E. (2000). Linear ablation lesions of unmappable ventricular tachycardia in patients with ischemic and nonischemic cardiomyopathy. Circulation Vol. 101:1288-1296

Marrouche NF, Groenewegen AS, Yang Y, Dibs S \& Scheinman MM. (2002). Clinical and electrophysiologic characteristics of left septal atrial tachycardia. J Am Coll Cardiol Vol. 40:1133-1139

Morady F \& Scheinman MM. (1984). Transvenous catheter ablation of posteroseptal accessory pathway in patients with Wolff-Parkinson-White syndrome. N Engl J Med Vol. 310:705-707

Morady F, Harvey M, Kalbfleisch SJ, El-Atassi R, Calkins H \& Langberg JJ. (1993) Radiofrequency catheter ablation of ventricular tachycardia in patients with coronary artery disease. Circulation Vol. 87:363-372

Nademanee K, McKenzie J, Kosar E, Schwab M, Sunsaneewitayakul B, Vasavakul T, Khunnawat C \& Ngarmukos T. (2004). A new approach for catheter ablation of atrial fibrillation: mapping of the electrophysiologic substrate. J Am Coll Cardiol Vol. 43:2044 -2053 
Nademanee K, Veerakul G, Chandanamattha P, Chaothawee L, Ariyachaipanich A, Jirasirirojanakorn K, Likittanasombat K, Bhuripanyo K \& Ngarmukos T. (2011). Prevention of ventricular fibrillation episodes in Brugada Syndrome by catheter ablation over the anterior right ventricular outflow epicardium. Circulation Vol. 123:1270-1279

Nakahara S, Tung R, Ramirez RJ, Michowitz Y, Vasedhi M, Buch E, Gima J, Wiener I, Mahajan A, Boyle NG \& Shivkumar K. (2010). Characterization of the arrhythmogenic substrate in ischemic and nonischemic cardiomyopathy. Implications for catheter ablation of hemodynamically unstable ventricular tachycardia. J Am Coll Cardiol Vol. 55:2355-2365

Natale A, Raviele A, Al-Ahmad A et al. (2010). Venice Chart international consensus document on ventricular tachycardia/fibrillation ablation. J Cardiovasc Electrophysiol Vol. 21:339-379

Nayak HM, Verdino RJ, Russo AM, Gerstenfeld EP, Hsia HH, Lin D, Dixit S, Cooper JM, Callans D \& Marchlinski FE. (2008). Ventricular tachycardia storm after initiation of biventricular pacing: incidence, clinical characteristics, management, and outcome. J Cardiovasc Electrophysiol Vol. 19:708-715

Nordbeck P, Seidl B, Fey B, Bauer WR \& Titter O. (2010). Effect of cardiac resynchronization therapy on the incidence of electrical storm. Int J Cardiol Vol. 143:330-336

Oral H, Scharf C, Chugh A, Hall B, Cheung P, Good E, Veerareddy S, Pelosi F \& Morady F. (2003). Catheter ablation for paroxysmal atrial fibrillation. Segmental pulmonary vein ostial ablation versus left atrial ablation. Circulation Vol. 108:2355-2360

Oral H, Pappone, Chugh A, Good E, Bogun F, Pelosi F, Bates ER, Lehmann MH, Vicedomini G, Augello G, Agricola E, Sala S, Santinelli V \& Morady F. (2006a). Circumferential pulmonary-vein ablation for chronic atrial fibrillation. $N$ Engl J Med Vol. 354:934941

Oral H, Chugh A, Good E, Sankaran S, Reich SS, Igic P, Elmouchi D, Tschopp D, Crawford T, Dey S, Wimmer A, Lemola K, Jongnarangsin K, Bogun F, Pelosi F \& Morady F. (2006b). A tailored approach to catheter ablation of paroxysmal atrial fibrillation. Circulation Vol. 113:1824-1831

Pappone C, Oreto G, Lamberti F, Vicedomini G, Loricchio ML, Shpun S, Rillo M, Calabro MP, Conversano A, Ben-Haim SA, Cappato R \& Chierchia S. (1999). Catheter ablation of paroxysmal atrial fibrillation using a 3D mapping system. Circulation Vol. 100:1203-1208

Pappone C, Rosanio S, Oreto G, Tocchi M, Gugliotta F, Vicedomini G, Sakvati A, Dicandia C, Mazzone P, Santinelli V, Gulletta S \& Chiechia S. (2000). Circumferentia radiofrequency ablation of PV ostia. Circulation Vol. 102:2619 -28

Pappone C, Manguso F, Vicedomini G, Gugliotta F, Santinelli O, Ferro A, Gulletta S, Sala S, Sora N, Paglino G, Augello G, Agricola E, Zngrillo A, Alfieri O \& Santinelli V. (2004). Prevention of iatrogenic atrial tachycardia after ablation of atrial fibrillation: a prospective randomized study comparing circumferential pulmonary vein ablation with a modified approach. Circulation Vol. 110:3036-3042

Pappone C, Augello G Sala S, Gugliotta F, Vicedomini G, Gulletta S, Paglino G, Mazzone P, Sora N, Greiss I, Santagostino A, LiVolsi L, Pappone N, Radinovic A, Manguso F \& Santinelli V. (2006). A randomized trial of circumferential pulmonary vein ablation 
versus antiarrhythmic drug therapy in paroxysmal atrial fibrillation. The APAF Study. J Am Coll Cardiol Vol. 48:2340-2347

Peichl P, Kautzner J, Cihak R, Vancura V \& Bytesnik J. (2003). Clinical application of electroanatomic mapping of "incisional" atrial tachycardia. Pacing Clin Electrophysiol Vol. 26:420-425

Poole JE, Johnson GW, Hellkamp AS, Anderson J, Callans DJ, Raitt MH, Reddy RK, Marchlinski FE, Yee R, Guarnieri T, Talajic M, Wilber DJ, Fishbein DP, Oacker DL, Matk DB, Lee KL \& Bardy GH. (2008). Prognostic importance of defibrillation shocks in patients with heart failure. N Engl J Med Vol. 259:1009-1017

Reddy V, Reynolds MR, Neuzil P, Richardson AW, Taborsky M, Jongnarangsin K, Kralovec S, Sediva L, Ruskin JN \& Josephson ME. (2007). Prophylactic catheter ablation for the prevention of defibrillator therapy. N Engl J Med Vol. 357:2657-2665

van Rees JB, Borleff JW, de Bie MK, Stijnen T, van Erven L, Bax JJ \& Schlij MJ. (2011). Inappropriate Implantable cardioverter-defibrllator shocks. Incidence, predictors, and impact on mortality. J Am Coll Cardiol Vol. 57:556-562

Sacher F, Roberts-Thomson K, Maury P, Tedrow U, Nault I, Steven D, Hocini M, Koplan B, Leroux L, Derval N, Seiler J, Wright MJ, Epstein L \& Haisaaguerre M. (2010). Epicardial ventricular tachycardia ablation. A multicenter safety study. J Am Coll Cardiol Vol. 55:2366-2376

Scheinman MM, Morady F, Hess DS \& Gonzalez R. (1982). Catheter-induced ablation of the atrioventricular junction to control refractory supraventricular arrhythmias. JAMA Vol. 248:851-855

Shpun S, Gepstein L, Hayam G \& Ben Haim SA. (1997). Guidance of radiofrequency endocardial ablation with real-time three-dimentional magnetic navigation system. Circulation Vol. 96:2016-2021

Smeets J, Ben Haim S, Ben David J, Gepstein L \& Josephson MM. (1996). Non-fluoroscopic endocardial mapping: first experience in patients. Pacing Clin Electrophysiol Vol. 9:627

Sra J, Bhatia A, Dhala A, Blanck Z, Deshpande S, Cooley R \& Akhtar M. (2001). Electroanatomically guided catheter ablation of ventricular tachycardia causing multiple defibrillation shocks. Pacing Clin Electrophysiol Vol. 24:1645-1652

Stevenson WG, Delacretaz E, Friedman PL \& Ellison KE. (1998). Identification and ablation of macroreentrant ventricular tachycardia with CARTO electroanatomic mapping system. Pacing Clin Electrophysiol Vol. 21:1448-1456

Stevenson WG, Friedman PL, Kocovic D, Sager PT, Saxon LA \& Pavri B. (1998). Radiofrequency catheter ablation of ventricular tachycardia after myocardial infarction. Circulation Vol. 98:308-314

Stevenson WG, Wilber DJ, Natale A, Jackman WM, Marchlinski FE, Talber T, GonzalesMD, Worley SJ, Daoud EG, Hwang C, Schuger C, Bump TE, Jazayeri M, Tomassoni GF, Koplelman HA, Soejima K, Nakagawa H \& for the Multicenter Thermocool VT Ablation Trial Investigators. (2008). Irrigated radiofrequency catheter ablation guided by electroanatomic mapping for recurrent ventricular tachycardia after myocardial infarction. The Multicenter Thermocool Ventricular Tachycardia Ablation Trial. Circulation Vol. 118:2773-2782

Takatsuki S, Mitamura H \& Ogawa S. (2001). Catheter ablation of monfocal premature ventricular complex trigerring idiopathic ventricular fibrillation. Heart Vol. 86:E3 
Takahashi Y, O'Neill MD, Hocini M, Reant P, Jonsson A, Jaïs P, Sanders P, Rostock T, Rotter M, Sacher F, Laffite S, Roudaut R, Clémenty J, MD \& Haïssaguerre M. (2007). Effect of stepwise ablation of chronic atrial fibrillation on atrial electrical and mechanical properties. J Am Coll Cardiol Vol. 49:1306-1314

Tedrow U \& Stevenson WG. (2009). Strategies for epicardial mapping and ablation of ventricular tachycardia. J Cardiovasc Electrophysiol Vol. 20:710-713

Tian J, Jeudy J, Smith MF, Jimenez A, Yin X, Bruce PA, Lei P, Turgeman A, Abbo A, Shenkhar R, Saba M, Shorofsky S \& Dickfeld T. (2001). Tree-dimensional contrastenhanced CT for anatomic, dynamic, and perfusion characterization of abnormal myocardium to guide ventricular tachycardia ablation. Circ Arrhythm Electrophysiol Vol. 3:496-504

Tung R, Josephson ME, Reddy V, Reynolds MR \& on behalf of the SMASH-VT investigators. (2010). Influence of clinical and procedural predictors on ventricular tachycardia ablation outcomes: An analysis from the substrate mapping and ablation in sinus rhythm to halt tachycardia trial (SMASH-VT). J Cardiovasc Electrophysiol Vol. 21:799803

Wolff L, Parkinson J \& White PD. (1930) Bundle-brunch block with short P-R interval in healthy young people prone to paroxysmal tachycardia. Am Heart J Vol. 5:685-704 


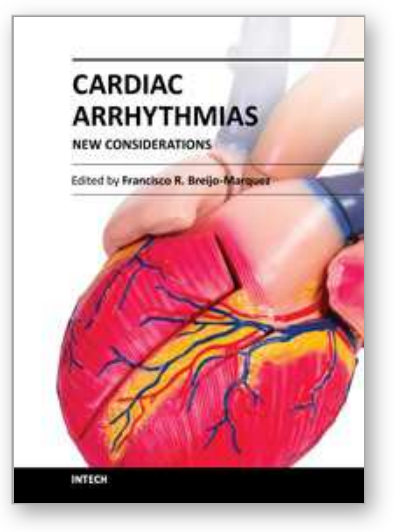

\author{
Cardiac Arrhythmias - New Considerations \\ Edited by Prof. Francisco R. Breijo-Marquez
}

ISBN 978-953-51-0126-0

Hard cover, 534 pages

Publisher InTech

Published online 29, February, 2012

Published in print edition February, 2012

The most intimate mechanisms of cardiac arrhythmias are still quite unknown to scientists. Genetic studies on ionic alterations, the electrocardiographic features of cardiac rhythm and an arsenal of diagnostic tests have done more in the last five years than in all the history of cardiology. Similarly, therapy to prevent or cure such diseases is growing rapidly day by day. In this book the reader will be able to see with brighter light some of these intimate mechanisms of production, as well as cutting-edge therapies to date. Genetic studies, electrophysiological and electrocardiographyc features, ion channel alterations, heart diseases still unknown , and even the relationship between the psychic sphere and the heart have been exposed in this book. It deserves to be read!

\title{
How to reference
}

In order to correctly reference this scholarly work, feel free to copy and paste the following:

Shimon Rosenheck, Jeffrey Banker, Alexey Weiss and Zehava Sharon (2012). Electromagnetic Mapping During Complex RF Ablations, Cardiac Arrhythmias - New Considerations, Prof. Francisco R. Breijo-Marquez (Ed.), ISBN: 978-953-51-0126-0, InTech, Available from: http://www.intechopen.com/books/cardiacarrhythmias-new-considerations/electroanatomic-mapping-the-approch-to-complex-arrhythmias

\section{INTECH}

open science | open minds

\section{InTech Europe}

University Campus STeP Ri

Slavka Krautzeka 83/A

51000 Rijeka, Croatia

Phone: +385 (51) 770447

Fax: +385 (51) 686166

www.intechopen.com

\section{InTech China}

Unit 405, Office Block, Hotel Equatorial Shanghai

No.65, Yan An Road (West), Shanghai, 200040, China

中国上海市延安西路65号上海国际贵都大饭店办公楼405单元

Phone: +86-21-62489820

Fax: +86-21-62489821 
(C) 2012 The Author(s). Licensee IntechOpen. This is an open access article distributed under the terms of the Creative Commons Attribution 3.0 License, which permits unrestricted use, distribution, and reproduction in any medium, provided the original work is properly cited. 